ARTICLE

\title{
Alarmin-painted exosomes elicit persistent antitumor immunity in large established tumors in mice
}

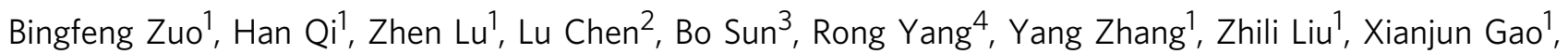
Abin You', Li Wu', Renwei Jing ${ }^{1}$, Qibing Zhou ${ }^{4} \&$ HaiFang Yin (1) ${ }^{1 \times}$

Treating large established tumors is challenging for dendritic cell (DC)-based immunotherapy. DC activation with tumor cell-derived exosomes (TEXs) carrying multiple tumorassociated antigen can enhance tumor recognition. Adding a potent adjuvant, high mobility group nucleosome-binding protein 1 (HMGN1), boosts DCs' ability to activate T cells and improves vaccine efficiency. Here, we demonstrate that TEXs painted with the functional domain of HMGN1 (TEX-N1ND) via an exosomal anchor peptide potentiates DC immunogenicity. TEX-N1ND pulsed DCs (DC tumor suppression in different syngeneic mouse models with large tumor burdens, most notably large, poorly immunogenic orthotopic hepatocellular carcinoma (HCC). DC show increased homing to lymphoid tissues and contribute to augmented memory $T$ cells. Importantly, N1ND-painted serum exosomes from cancer patients also promote DC activation. Our study demonstrates the potency of TEX-N1ND to strengthen DC immunogenicity and to suppress large established tumors, and thus provides an avenue to improve DC-based immunotherapy.

\footnotetext{
${ }^{1}$ Key Laboratory of Immune Microenvironment and Disease (Ministry of Education) \& Tianjin Key Laboratory of Cellular Homeostasis and Human Diseases \& Department of Cell Biology, Tianjin Medical University, Qixiangtai Road, Heping District, Tianjin 300070, China. ${ }^{2}$ Department of Hepatobiliary, Tianjin Medical University Cancer Institute and Hospital, National Clinical Research Center for Cancer, Key Laboratory of Cancer Prevention and Therapy, Tianjin 300060, China. ${ }^{3}$ Department of The Second Department of Breast Cancer, Tianjin Medical University Cancer Institute and Hospital, National Clinical Research Center for Cancer, Key Laboratory of Cancer Prevention and Therapy, Tianjin 300060, China. ${ }^{4}$ Department of Nanomedicine \& Biopharmaceuticals, National Engineering Research Center for Nanomedicine, Huazhong University of Science and Technology, Wuhan, 430074 Hubei Province, China. ${ }^{凶}$ email: haifangyin@tmu.edu.cn
} 
$\mathrm{D}$ endritic cell (DC)-based cancer immunotherapy relies on activation of DCs as antigen-presenting cells by tumor antigens or lysates to stimulate an adaptive immunological response against tumors. This has shown promise for cancer patients with sipuleucel- $\mathrm{T}$, which was approved for advanced prostate cancer ${ }^{1,2}$, as a typical example. However, DC vaccines currently being investigated in trials are somewhat underwhelming with the overall objective response rate rarely exceeding $15 \%{ }^{3}$. However, DC vaccines have good safety profiles and the potential to induce innate and adoptive antitumor immunity for long-term efficacy, thus one of the emerging trends in DC vaccine research is to improve the immunogenicity of next-generation DC vaccines ${ }^{4}$ according to registered DC clinical trials. Inducers that enhance the immunogenicity of exogenous DCs through ex vivo activation of these cells prior to immunization are under intensive scrutiny ${ }^{5}$, and the implementation of next-generation DC vaccines with improved activities might hold the key to fulfilling the therapeutic potential of DC-based immunotherapy.

Maturation cocktails and other immunoadjuvants can be used to promote the immunostimulatory activity of exogenously activated $\mathrm{DCs}^{6-8}$. The nature of immunoadjuvants determines the type, the magnitude, the breadth, and the quality of antitumor immune response ${ }^{9}$. DC vaccines that induce a bias towards a Th1 immune response appear to elicit stronger activation of tumorspecific cytotoxic T lymphocytes and natural killer (NK) cells and only tumor-associated antigen (TAA)-specific Th1 immune responses are protective against tumors ${ }^{10,11}$, thus adjuvants that promote this bias are preferred. High-mobility group nucleosome-binding protein 1 (HMGN1) improves DC maturation and activation in response to exogenous antigens and consistently induces Th1 immune responses ${ }^{12}$. Hence HMGN1 has been harnessed to promote generation of antitumor immune responses as DNA vaccines or in combination with chemotherapeutic agents and activators/checkpoint inhibitors in different tumor models ${ }^{13-15}$. However, only limited effects were achieved with DNA vaccines and combinatorial therapy since HMGN1 required intratumoral administration, which is not clinically applicable to most tumors. Therefore, efficient systemic delivery of HMGN1 to cells is needed to unlock the full therapeutic potential of HMGN1 as an immunoadjuvant.

Recently, tumor-derived exosomes (TEXs), which harbor multiple TAAs to provide a broad spectrum of antigen presentation, have drawn much interest as antigens for DC-based immunotherapy ${ }^{16-18}$. TEXs, particularly patient-derived TEXs, have good biocompatibility, low immunogenicity, and high penetration of biological barriers, thus TEXs are good activators of DC vaccines. It was previously shown that covalent linkage of an alarmin to a target TAA could better promote TAA-specific immune responses and immunoprotection ${ }^{13,14}$. Ideally, a method that combines delivery of molecular adjuvants with the TAAenriched exosomes would improve the immunogenicity of DC immunotherapy and consequently, potential therapeutic outcome.

Here, we covalently link the functional $\mathrm{N}$-terminal domain of HMGN1 (N1ND) to CP05, a recently identified exosomal anchor peptide which allows direct and efficient cargo loading on exosomes ${ }^{12,19}$, and paint N1ND on TEXs (TEX-N1ND). DCs

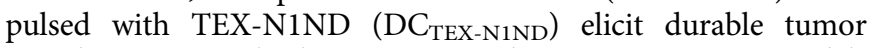
retardation in multiple syngeneic subcutaneous tumor models bearing large, established tumor burdens, and also in poorly immunogenic orthotopic hepatocellular carcinoma (HCC) mice with large tumor loads. Importantly, TEX-N1ND also augments human DC immunogenicity against different patient-derived cancer cells in vitro. Altogether TEX-N1ND heightens the immunostimulatory activities of DCs and migration to lymph nodes, consequently accelerating the generation of long-lived protective $\mathrm{T}$ cell memory response, which is responsible for the persistent antitumor immunity of activated DCs.

\section{Results}

N1ND-painted TEX promotes N1ND uptake and DCs' immunity. Motivated by HMGN1's efficacy at inducing Th1 antitumor immune response and our recently discovered strategy for intracellular delivery of cargoes $12,13,19$, we explored the feasibility of painting the surface of TEX with the functional Nterminus of HMGN1 (N1ND) using CD63-binding peptide (CP05) (TEX-N1ND). Incubation of DCs with TEX-N1ND can deliver N1ND into cells to enhance TEX-mediated DC activation and immunogenicity in different tumor models. To determine whether preexisting HMGN1 levels in TEXs would have any impact on the effect of additional N1ND on DC activation, we assayed TEXs, with a buoyant density of $1.13-1.23 \mathrm{~g} \mathrm{ml}^{-1}$ (Supplementary Fig. 1a), from murine pancreatic cancer (Panc02), Lewis lung cancer (LLC1), lymphoma (EL4), breast cancer (4T1), HCC (Hepa1-6) cells, and DCs for HMGN1 (Fig. 1a). The levels of HMGN1 in TEXs generally correlated with their parental cells (Supplementary Fig. 1b). TEXs from Hepa1-6, 4T1, and Panc02 were selected as representative TEXs containing no, medium, or high levels of HMGN1 respectively for subsequent studies. AF680-labeled N1ND-CP05 efficiently bound to TEXs, with the highest binding efficiency to $\mathrm{TEX}_{\mathrm{Hepa}}(88.1 \%)$ (Fig. 1b), correlating with the percentage of CD63-positive TEXs (Supplementary Fig. 1c) without altering the morphology of TEXs (Supplementary Fig. 1d). In contrast, only trace binding was

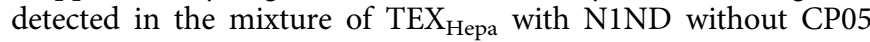
(Fig. 1b, TEX $\mathrm{Hepa} / \mathrm{N} 1 \mathrm{ND}$ ), demonstrating that N1ND binds TEXs due to CP05. Dramatically increased uptake of AF680-labeled N1ND-CP05 was observed in bone marrow-derived DCs (BMDC) after incubation with TEX (TEX-N1ND) $\left(40 \mu \mathrm{g} \mathrm{ml}^{-1}\right)$ (BMDC ${ }_{\text {TEX-N1ND }}$ ) when compared with the mixture of TEXs with N1ND without CP05 $\left(\mathrm{BMDC}_{\mathrm{TEX} / \mathrm{N} 1 \mathrm{ND}}\right)$ or N1ND-CP05 alone $\left(\mathrm{BMDC}_{\mathrm{N} 1 \mathrm{ND}}\right)$ (Fig. 1c and Supplementary Fig. 1e), suggesting that binding to TEXs enabled efficient delivery of N1ND-CP05 to cells. Major histocompatibility complex class (MHC) I/II, costimulatory molecules (Fig. 1d, e) and tumor necrosis factor- $\alpha$ (TNF- $\alpha$ ) (Fig. 1f), a proinflammatory cytokine induced by HMGN1, were significantly upregulated in DCs treated with TEX-N1ND compared with the controls. Importantly, TEXN1ND induced comparable DC activation in different TEXs independent of endogenous HMGN1 levels. Secreted levels of interferon- $\gamma \quad(\mathrm{IFN}-\gamma)$ and interleukin-2 (IL-2) consistently increased in splenic naive $T$ cells stimulated with $B M D C_{\text {TEX-N1ND }}$ (Fig. 1g), resulting in significantly higher cytolysis rates against parental tumor cells, from which TEXs were derived, compared with other controls (Fig. 1h), indicating that N1ND is capable of activating DCs in vitro and increasing the immunogenicity of the DCs.

N1ND enhances TEX-induced DC immunity on large tumors. Treating large established tumors, which closely mimic the typical clinical presentation of patients, remains a challenge for initial DC-based immunotherapy, thus we evaluated BMDC $_{\text {TEX-N1ND }}$ in three different subcutaneous syngeneic tumor models: Hepa1-6 HCC, Panc02 pancreatic cancer, and 4T1 breast cancer. Tumor cells $\left(2 \times 10^{6}\right)$ were injected subcutaneously and allowed to grow for 14 days to $\sim 40-60 \mathrm{~mm}^{2}$ depending on tumor type before initiation of therapy. $\mathrm{BMDC}_{\mathrm{TEX}-\mathrm{N} 1 \mathrm{ND}}, \mathrm{BMDC}_{\mathrm{TEX} / \mathrm{N} 1 \mathrm{ND}}$, or BMDC $_{\text {TEX }}\left(2 \times 10^{6}\right)$ were administered intravenously once per week for 3 weeks, a protocol identical to our previous study ${ }^{18}$. Robust and persistent tumor growth inhibition with very similar residual and significantly smaller tumor sizes than other groups 
a

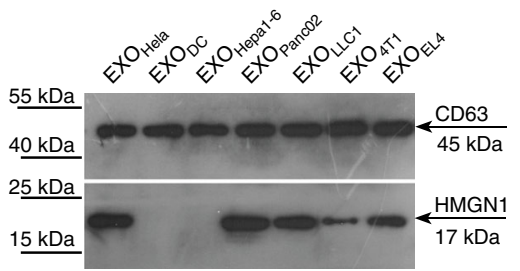

C

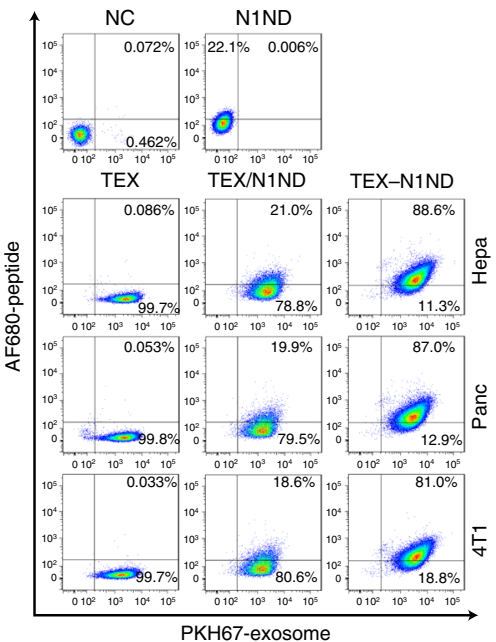

b

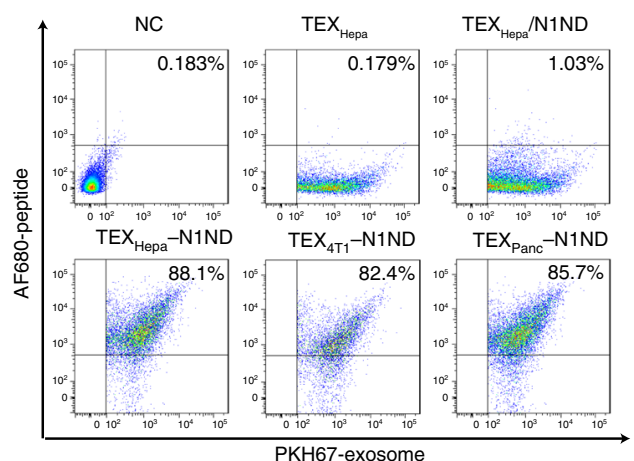

d

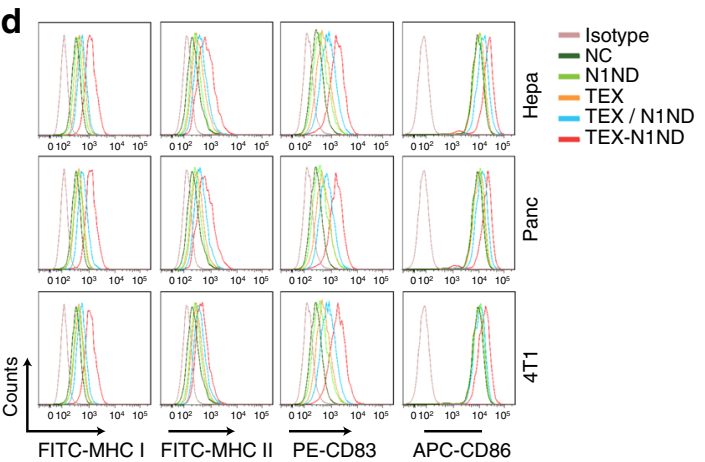

e
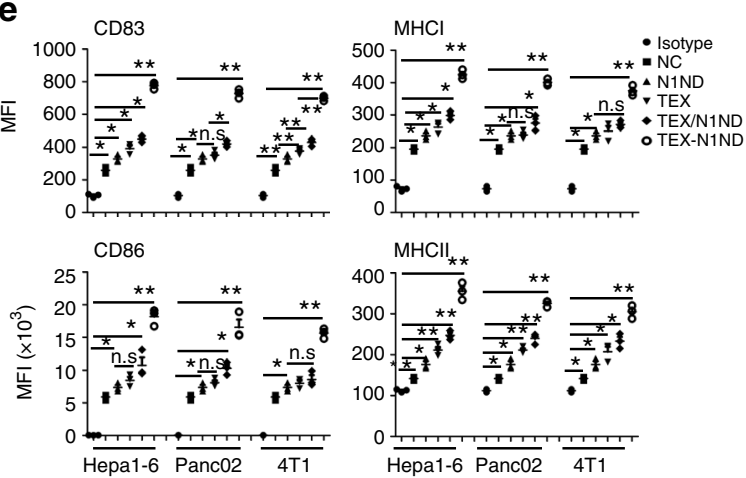

g
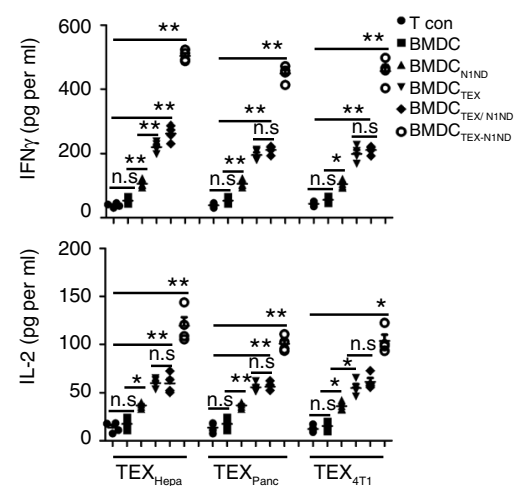

f
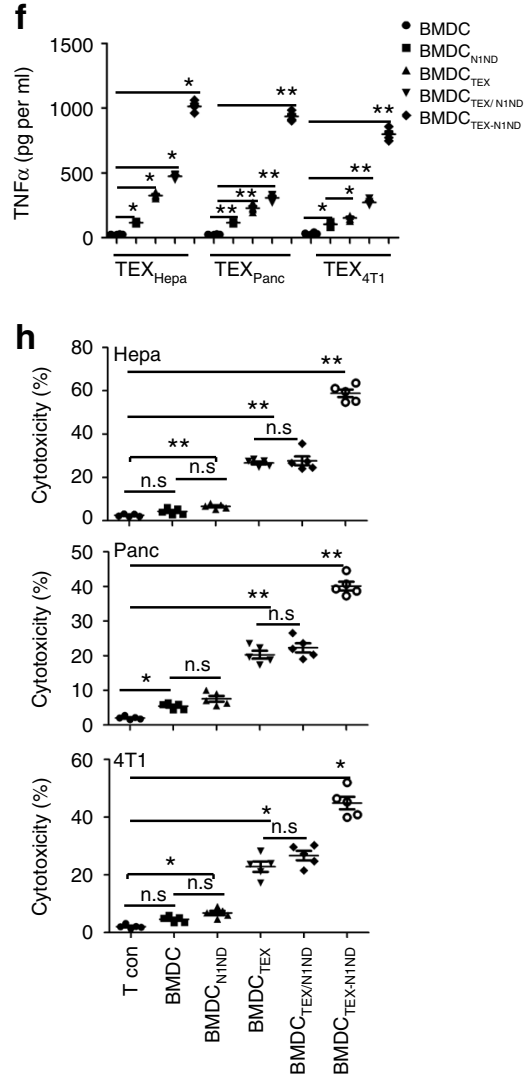

(Fig. 2a) was achieved in HCC tumor-bearing mice treated with $\mathrm{BMDC}_{\text {TEX-N1ND }} 42$ days after tumor challenge; whereas $\mathrm{BMDC}_{\mathrm{TEX} / \mathrm{N} 1 \mathrm{ND}}$ or $\mathrm{BMDC}_{\mathrm{TEX}}$ elicited weaker responses with higher variability. Increased $\mathrm{CD}^{+}$and reduced $\mathrm{CD} 4^{+} \mathrm{CD} 25^{+}$ regulatory $\mathrm{T}$ cells (Tregs) were consistently detected in blood and tumor tissues from mice treated with BMDC $\mathrm{TEX}_{\mathrm{TEN} \text { ND }}$ compared with other groups (Fig. 2b, c and Supplementary Fig. 2a, b). In contrast, no significant change was found for B cells across different treatment groups (Fig. 2b, c). Similarly, durable tumor retardation was observed for Panc02 and $4 \mathrm{~T} 1$ subcutaneous tumor-bearing mice treated with $\mathrm{BMDC}_{\mathrm{TEX}-\mathrm{N} 1 \mathrm{ND}}$ compared with other groups on day 42 (Fig. 2d, e) with similar shifts in circulatory and tumor $\mathrm{CD}^{+} \mathrm{T}$ cells and Tregs (Fig. 2f, g), suggesting that the strategy is broadly applicable across tumor types. 
Fig. 1 HMGN1 expression in TEXs and in vitro assessment of TEX-N1ND. a Western blot analysis for detecting the expression of HMGN1 in TEXs derived from different tumor cells. Total protein $(20 \mu \mathrm{g})$ was loaded for TEXs. Exosomes from Hela $\left(E X O_{H e l a}\right)$ and DCs $\left(E X O_{D C}\right)$ were used as positive and negative controls, respectively. CD63 was used as an exosomal marker protein. This experiment was repeated once (two in total). b Quantitative analysis on the

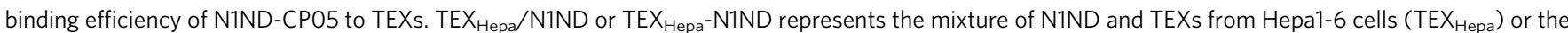

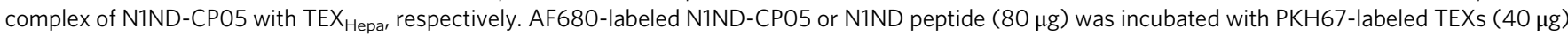
for $12 \mathrm{~h}$. Free peptide was removed by diafiltration. NC refers to unlabeled TEX Hepa. $_{\text {c }}$ Flow cytometric analysis of TEX-N1ND uptake in BMDCs at $24 \mathrm{~h}$ after incubation. NC refers to untreated DCs. Levels (d) and quantitative analysis (e) of surface markers and co-stimulatory molecules in BMDC TEX-N1ND, $\mathrm{BMDC}_{\mathrm{TEX} / \mathrm{N} 1 \mathrm{ND}}$, or BMDC $\mathrm{BEX}_{\mathrm{TEX}}(n=3$; one-way ANOVA post hoc Student-Newman-Keuls test). NC refers to untreated DCs. $\mathbf{f}$ Measurement of TNF- $\alpha$ secretion in supernatants of $\mathrm{BMDC}_{\mathrm{TEX}}, \mathrm{BMDC}_{\mathrm{TEX} / \mathrm{N} 1 \mathrm{ND}}$, or $\mathrm{BMDC}_{\mathrm{TEX}-\mathrm{N} 1 \mathrm{ND}}(n=4$; one-way ANOVA on ranks). $\mathrm{g}$ Analysis of IFN- $\gamma$ and IL-2 in supernatants from splenic T lymphocytes activated by BMDC $\mathrm{TEX}_{\mathrm{T} \text { 1ND, }} \mathrm{BMDC}_{\mathrm{TEX} / \mathrm{N} 1 \mathrm{ND}}$, or $\mathrm{BMDC}_{\mathrm{TEX}}(n=4$; one-way ANOVA post hoc Student-Newman-Keuls test).

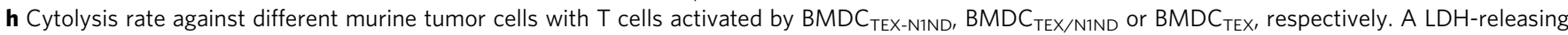
cytotoxic assay was performed to measure the cytolysis efficiency of effector $T$ cells activated by $B M D C_{T E X-N 1 N D}, B M D C_{T E X / N 1 N D}$, or $B M D C_{T E X}$, respectively in Hepa1-6, Panc02 ( $n=5$; one-way ANOVA post hoc Student-Newman-Keuls test) and 4 T1 cells (one-way ANOVA on ranks). N refers to the number of individual biological replicate unless otherwise specified. Data are presented as means \pm s.e.m. $\left({ }^{\star} p<0.05 ;{ }^{\star \star} p<0.001 ; n . s\right.$ not significant). Source data are provided as a Source Data file.

Notably, consistent with the previous study ${ }^{18}$, a cross-protective effect was observed in mice bearing subcutaneous HCC treated with $\mathrm{DC}_{\mathrm{TEX}(\mathrm{Panc})-\mathrm{N} 1 \mathrm{ND}}$ (Supplementary Fig. 2c, d), and the presence of N1ND did not influence the antigen-specific immune response elicited by TEXs as demonstrated by significant increases in alpha-fetoprotein (AFP)-specific $\mathrm{CD}^{+} \mathrm{T}$ cells (Supplementary Fig. 2e) and in levels of IFN- $\gamma$ and IL-2 upon stimulation with AFP212 (Supplementary Fig. 2f), an identified murine AFP epitope ${ }^{20}$, in culture supernatants of splenic $\mathrm{T}$ lymphocytes from mice bearing subcutaneous HCC treated with $\mathrm{DC}_{\mathrm{TEX}(\mathrm{Hepa})-\mathrm{N} 1 \mathrm{ND}}$ but not with $\mathrm{DC}_{\mathrm{TEX}(\mathrm{Panc})^{-}}$or $\mathrm{DC}_{\mathrm{TEX}(4 \mathrm{~T} 1)-\mathrm{N} 1 \mathrm{ND}}$. Importantly, a hierarchy of efficacy was observed with different $\mathrm{BMDC}_{\mathrm{TEX}-\mathrm{N} 1 \mathrm{ND}}$ in three tumor models and was inversely correlated with the endogenous expression of HMGN1 in TEXs, with TEXs derived from HCC cells showing the greatest efficacy, implying that $\mathrm{DC}_{\mathrm{TEX}-\mathrm{N} 1 \mathrm{ND}}$ is likely more effective for tumors without or with lower expression of HMGN1.

DC $_{\text {TEX-N1ND }}$ induce persistent retardation of orthotopic HCC. To understand the cellular and molecular mechanisms underlying the observed therapeutic effect of $\mathrm{DC}_{\mathrm{TEX}-\mathrm{N} 1 \mathrm{ND}}$, we analyzed responses to $\mathrm{DC}_{\mathrm{TEX}-\mathrm{N} 1 \mathrm{ND}}$ in an immunosuppressive, poorly immunogenic Hepa1-6 HCC model. Subcutaneous tumors do not faithfully recapitulate the histology and complexity of HCC, thus we employed two different orthotopic HCC mouse models bearing large tumor loads. A day-7 HCC model was generated by transplanting more tumor tissues to accelerate the formation of large tumors $(0.68 \pm 0.02$ in longitudinal diameter $)$ within 7 days, and another with tumor loads $(0.55 \pm 0.04$ in longitudinal diameter) formed in 21 days (day-21) by transplanting fewer tumor tissues to allow the formation of immunosuppressive microenvironment (Supplementary Fig. 3a). Tumors grew progressively in day-7 orthotopic HCC mice resulting in $100 \%$ lethality in untreated mice by day 35, replacing most of the livers (Supplementary Fig. 3b-e). Three weekly intravenous doses of $\mathrm{DC}_{\text {TEX-N1ND }}$ $\left(2 \times 10^{6}\right)$ significantly inhibited tumor growth and extended the lifespan of tumor-bearing mice as tumor volume and mass were significantly reduced and survival rate increased compared with other groups (Supplementary Fig. 3c-e). Persistent tumor retardation was observed in mice treated with DC $_{\text {TEX-N1ND }}$ compared with other groups on day 32 and 46 (Supplementary Fig. 3c, d), demonstrating that N1ND-CP05 enhanced activated DCs' antitumor immunity. Concordantly, in the day-21 orthotopic HCC mice, DC $_{\text {TEX-N1ND }}\left(2 \times 10^{6}\right)$ promoted robust and sustained inhibition of induced tumors compared with mice treated with $\mathrm{DC}_{\mathrm{TEX}}$, with a $60 \%$ survival rate at week 9 vs. $0 \%$ for $\mathrm{DC}_{\mathrm{TEX}}$ (Fig. 3a-d). Real-time monitoring of tumor growth via magnetic resonance imaging (MRI) revealed progressive tumor growth and multiple nodular foci formation in $\mathrm{DC}_{\mathrm{TEX}}$-treated and untreated mice, whereas no evident tumor progression was found in mice treated with $\mathrm{DC}_{\mathrm{TEX}-\mathrm{N} 1 \mathrm{ND}}$ (Fig. $3 \mathrm{c}, \mathrm{d}$ ), demonstrating that $\mathrm{DC}_{\mathrm{TEX}-}$ N1ND results in sustainable tumor inhibition. Strikingly, no pulmonary metastasis was found in tumor-bearing mice treated with $\mathrm{DC}_{\mathrm{TEX}-\mathrm{N} 1 \mathrm{ND}}$ at week 9; in contrast, prominent pulmonary metastasis was established in $\mathrm{DC}_{\mathrm{TEX}}$-treated mice (Fig. 3e). These findings demonstrate that TEX-N1ND activates DCs to induce greater antitumor immunity.

DC $_{\text {TEX-N1ND }}$ reshape orthotopic HCC microenvironment in mice. The tumor microenvironment plays a crucial role in tumor progression and prognosis ${ }^{21}$, therefore modulation of the tumor microenvironment may augment the antitumor immune response. To determine the effect of $\mathrm{DC}_{\mathrm{TEX}-\mathrm{N} 1 \mathrm{ND}}$ on the tumor microenvironment, we examined $\mathrm{CD}^{+} \mathrm{T}$ cells in blood and tumor tissues from day-21 orthotopic HCC mice treated with $\mathrm{DC}_{\mathrm{TEX}-\mathrm{N} 1 \mathrm{ND}}$ as $\mathrm{DC}_{\mathrm{TEX}}$ and HMGN1 were shown to function primarily via stimulation of $\mathrm{CD}^{+} \mathrm{T}$ cells and increased IFN- $\gamma$ secretion ${ }^{13}$. Significant increases in $\mathrm{CD}^{+} \mathrm{T}$ cells and declines in $\mathrm{CD} 4{ }^{+} \mathrm{CD} 25^{+}$Tregs were detected in blood and tumors from mice treated with $\mathrm{DC}_{\mathrm{TEX}-\mathrm{N} 1 \mathrm{ND}}$ compared with other groups (Fig. $4 \mathrm{a}, \mathrm{b}$ ), indicating that $\mathrm{DC}_{\text {TEX-N1ND }}$ primarily promotes $\mathrm{CD}^{+} \mathrm{T}$ cell priming. Active recruitment of effector $\mathrm{CD} 3^{+} \mathrm{T}$ lymphocytes to primary tumor sites in orthotopic HCC mice was observed in tumor cross-sections from $\mathrm{DC}_{\mathrm{TEX}-\mathrm{N} 1 \mathrm{ND}}$-treated mice compared with $\mathrm{DC}_{\mathrm{TEX}}$ at different time-points, and fewer effector $\mathrm{T}$ cells were detected in PBS-treated mice on week 7 (Fig. 4c). Sporadic and significantly fewer FoxP3 ${ }^{+}$Tregs were found in $\mathrm{DC}_{\mathrm{TEX}-\mathrm{N} 1 \mathrm{ND}^{-}}$ treated samples compared with other groups (Fig. 4c, d). Level of IFN- $\gamma$ significantly rose and TGF- $\beta$ and IL-10 levels were significantly reduced in tumor tissues and blood from $\mathrm{DC}_{\mathrm{TEX}-\mathrm{N} 1 \mathrm{ND}^{-}}$ treated mice, compared with $\mathrm{DC}_{\mathrm{TEX}}$ and PBS groups (Fig. $4 \mathrm{e}, \mathrm{f}$, and Supplementary Fig. 4a, b). Overall, these data demonstrate that $\mathrm{DC}_{\mathrm{TEX}-\mathrm{N} 1 \mathrm{ND}}$ can induce persistent antitumor immunity and reshape tumor microenvironment in orthotopic HCC mice bearing large established tumor burdens.

TEX-N1ND boosts memory $T$ cells for long-lasting immunity. Generation of memory $\mathrm{CD}^{+} \mathrm{T}$ cells can greatly enhance protective immunity ${ }^{22}$ and thus is an important goal of vaccination. Given the critical role of $\mathrm{CD}^{+}{ }^{+} \mathrm{T}$ cells in the therapeutic effect, we first analyzed the effect of $\mathrm{DC}_{\mathrm{TEX}-\mathrm{N} 1 \mathrm{ND}}$ on circulatory memory T cells from treated mice. Strikingly, significantly greater amplification of effector and memory $\left(\mathrm{CD} 8^{+} \mathrm{CD} 44^{\text {high }}\right) \mathrm{T}$ cells, particularly $\mathrm{CD} 8^{+} \mathrm{CD} 44^{\text {high }} \mathrm{CD} 127^{\text {high }}$ long-lived memory $\mathrm{T}$ cells ${ }^{23-25}$, occurred in mice receiving $\mathrm{DC}_{\mathrm{TEX}-\mathrm{N} 1 \mathrm{ND}}$ treatment on 
a
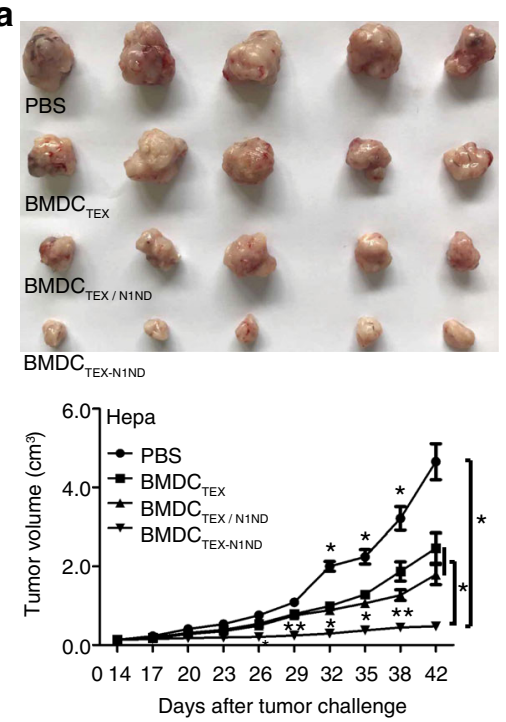

d
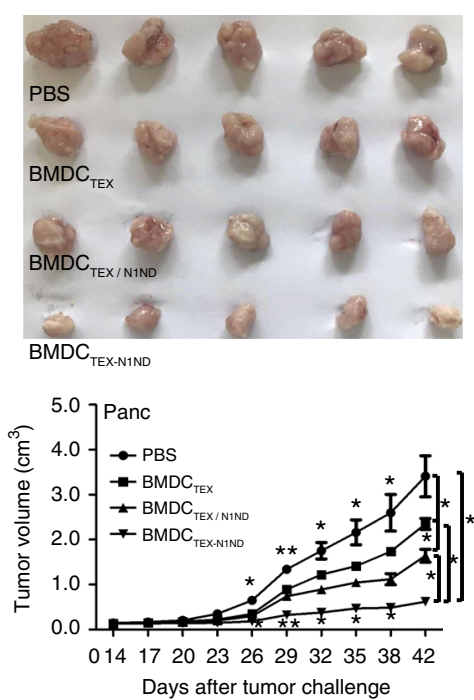

f

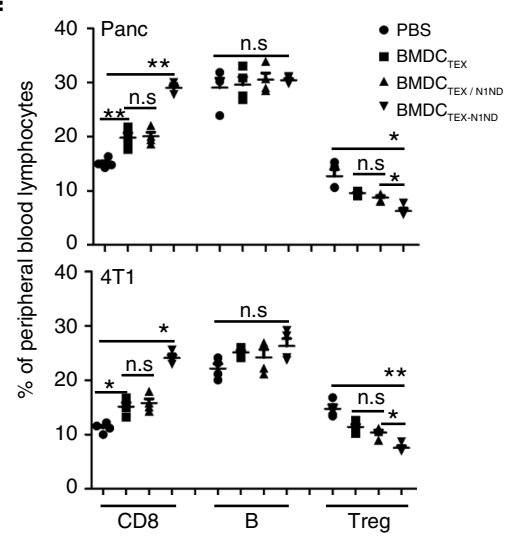

week 7 and 9, compared with corresponding $\mathrm{DC}_{\mathrm{TEX}}$ and $\mathrm{PBS}$ treatment groups (Fig. 5a). DC $\mathrm{DCXX}_{\mathrm{TEN} \text { ND }}$ treatment also elicited significantly more circulatory $\mathrm{CD} 8^{+}$effector memory $\mathrm{T}$ cells ( $\mathrm{T}_{\mathrm{EM}}$; $\mathrm{CD} 44^{\text {high }} \mathrm{CD} 62 \mathrm{~L}^{\text {low }}$ ) on week 7 and $9^{24}$, compared with $\mathrm{DC}_{\mathrm{TEX}}$ and PBS treatment (Fig. $5 \mathrm{~b}$ ), suggesting that increased $\mathrm{T}_{\mathrm{EM}}$ cells contributed to the long-lasting protective immunity. Consistently, the proportion of $\mathrm{CD} 8^{+} \mathrm{CD} 44^{\text {high }}$ and $\mathrm{CD} 8^{+}$ $\mathrm{CD} 44^{\text {high }} \mathrm{CD} 127^{\text {high }}$ memory $\mathrm{T}$ cells, particularly $\mathrm{T}_{\mathrm{EM}}$ and $\mathrm{CD} 8^{+}$
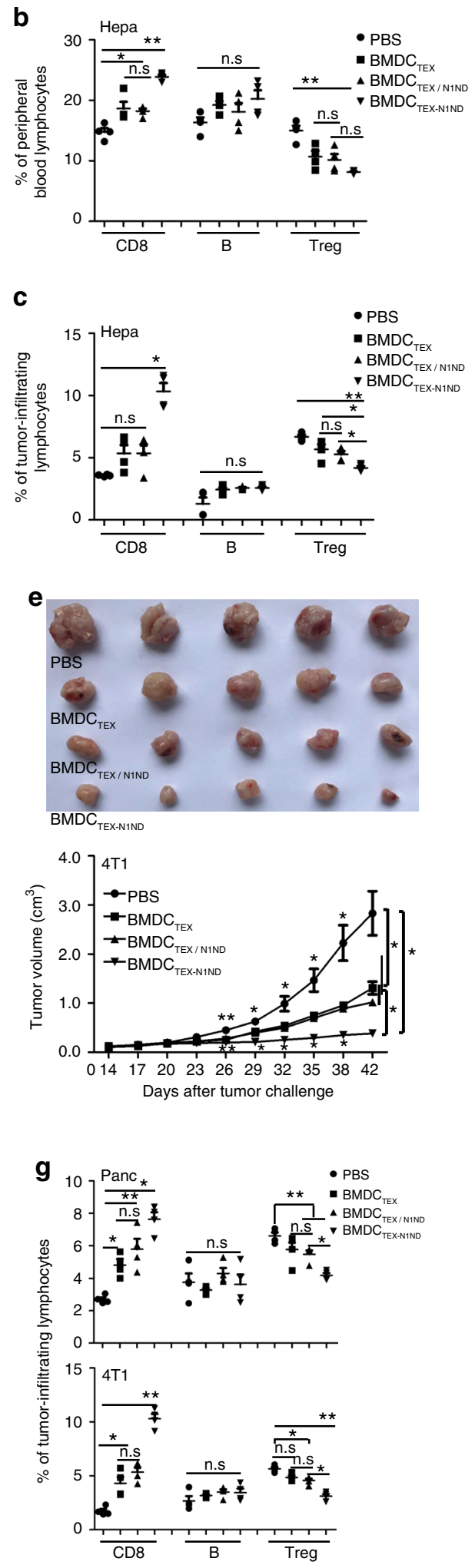

central memory $\mathrm{T}$ cells $\left(\mathrm{T}_{\mathrm{CM}}\right.$; $\left.\mathrm{CD} 44^{\text {high }} \mathrm{CD} 62 \mathrm{~L}{ }^{\text {high }}\right)$, significantly increased in the secondary lymphoid tissue (spleen) from

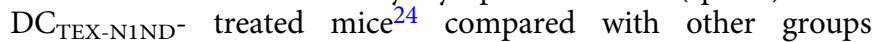
(Fig. 5c, d and Supplementary Fig. 5a). To ascertain if memory $\mathrm{T}$ cells induced by repeated $\mathrm{DC}_{\mathrm{TEX}-\mathrm{N} 1 \mathrm{ND}}$ vaccination accounted for the prolonged antitumor immunity observed, we immunized C57BL/6 mice with $\mathrm{DC}_{\mathrm{TEX}-\mathrm{N} 1 \mathrm{ND}}\left(2 \times 10^{6}\right)$ intravenously once per week for 3 weeks. As expected, circulatory effector and memory 


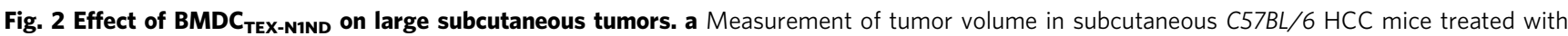
$\mathrm{BMDC}_{\mathrm{TEX}-\mathrm{N} 1 \mathrm{ND}}, \mathrm{BMDC}_{\mathrm{TEX} / \mathrm{N} 1 \mathrm{ND}}$, or BMDC $\mathrm{BEX}_{\mathrm{TEX}}\left(2 \times 10^{6}\right.$ cells once per week for 3 weeks $)$ at day $26(n=5$; one-way ANOVA on ranks), day 29 ( $n=5$; oneway ANOVA post hoc Student-Newman-Keuls test), day 32 and day 35 ( $n=5$; one-way ANOVA on ranks), day 38 ( $n=5$; one-way ANOVA post hoc Student-Newman-Keuls test) and day 42 ( $n=5$; one-way ANOVA on ranks). TEXs were derived from murine Hepa1-6 cells. Flow cytometric analysis of different immune cells in blood (b) or tumor tissues (c) from HCC mice treated with BMDC $\mathrm{TEX}_{\mathrm{N} \text { NND, }} \mathrm{BMDC}_{\mathrm{TEX} / \mathrm{N} 1 \mathrm{ND},}$, or $\mathrm{BMDC}_{\mathrm{TEX}}, \mathrm{respectively}(n=4$; one-way ANOVA post hoc Student-Newman-Keuls test; $n$ represents the number of animals used for each group). Measurement of tumor volume in syngeneic subcutaneous C57BL/6 pancreatic cancer mice (d) or BALB/C breast cancer mice (e) treated with $\mathrm{BMDC}_{\mathrm{TEX}-\mathrm{N} 1 \mathrm{ND}}, \mathrm{BMDC}_{\mathrm{TEX} / \mathrm{N} 1 \mathrm{ND}}$, or $_{\mathrm{BMDC}} \mathrm{CTEX}_{\mathrm{T}}$ $\left(2 \times 10^{6}\right.$ cells once per week for 3 weeks) day $26(n=5$; one-way ANOVA post hoc Student-Newman-Keuls test), day 29 ( $n=5$; one-way ANOVA post hoc Student-Newman-Keuls test), day 32, 35, and $42(n=5$; one-way ANOVA on ranks). TEXs were derived from murine pancreatic or breast cancer cells. Flow cytometric analysis of different immune cells in blood (f) or tumor tissues $(\mathbf{g})$ from subcutaneous tumor mice treated with BMDC TEX-NiND, $\mathrm{BMDC}_{\mathrm{TEX} / \mathrm{N1ND}}$, or $\mathrm{BMDC}_{\mathrm{TEX}}\left(n=4\right.$; one-way ANOVA post hoc Student-Newman-Keuls test). Data are presented as means $\pm \mathrm{s} . \mathrm{e} . \mathrm{m}$. $\left({ }^{\star} p<0.05 ;{ }^{\star \star} p<\right.$ 0.001 ; n.s not significant). Source data are provided as a Source Data file.

$\mathrm{T}$ cells, particularly long-lived memory $\mathrm{T}$ cells, significantly increased in $\mathrm{DC}_{\mathrm{TEX}-\mathrm{N} 1 \mathrm{ND}}$-treated mice, whereas to a lesser extent in $\mathrm{DC}_{\mathrm{TEX}}$ compared with PBS controls (Fig. 5e and Supplementary Fig. $5 \mathrm{~b}$ ), indicating that $\mathrm{DC}_{\mathrm{TEX}-\mathrm{N} 1 \mathrm{ND}}$ is potent at triggering the generation of memory $\mathrm{T}$ cells. Circulatory $\mathrm{T}_{\mathrm{EM}}$ cells were also significantly elevated in $\mathrm{DC}_{\mathrm{TEX}-\mathrm{N} 1 \mathrm{ND}}$-treated mice, compared with other groups (Fig. 5f). Correspondingly, persistent tumor inhibition and effector $\mathrm{T}$ cells infiltration into tumor sites were observed in $\mathrm{DC}_{\mathrm{TEX}-\mathrm{N} 1 \mathrm{ND}}$-immunized $\mathrm{C} 5 \mathrm{~B} \mathrm{BL} / 6$ mice 4 weeks after tumor challenge with Hepa1-6 cells $\left(5 \times 10^{5}\right)$ injected subcutaneously as tumor volume and weight significantly decreased (Fig. 5g, h) and $\mathrm{CD}^{+}$effector $\mathrm{T}$ and $\mathrm{T}_{\mathrm{EM}}$ cells significantly increased in tumor tissues (Fig. 5i), and memory $\mathrm{T}$ cells in blood (Supplementary Fig. 5c, d) and the spleen (Supplementary Fig. 5e) significantly rose. To further confirm the direct involvement of memory $\mathrm{T}$ cells in the long-lasting antitumor immunity triggered by $\mathrm{DC}_{\mathrm{TEX}-\mathrm{N} 1 \mathrm{ND}}$, we isolated $\mathrm{T}_{\mathrm{EM}}$ and $\mathrm{T}_{\mathrm{CM}}$ from $C 57 B L / 6$ mice immunized with $\mathrm{DC}_{\mathrm{TEX}-\mathrm{N} 1 \mathrm{ND}}$ under identical conditions as described above and intravenously administered $\mathrm{T}_{\mathrm{EM}}$ or $\mathrm{T}_{\mathrm{CM}}(5 \times$ $10^{6}$ ) into day-7 orthotopic HCC mice for single injection. Strikingly, tumor growth was significantly inhibited in $\mathrm{T}_{\mathrm{EM}^{-}}$and $\mathrm{T}_{\mathrm{CM}^{-}}$ treated HCC mice compared with untreated controls (Fig. 5j), strengthening the notion that memory $\mathrm{T}$ cell induction mediated protective immunity against the tumor. These findings support the conclusion that memory $\mathrm{T}$ cells boosted by $\mathrm{DC}_{\mathrm{TEX}-\mathrm{N} 1 \mathrm{ND}}$ contribute to long-lasting protective immune response.

DC activation and lymph node homing boosts immune memory. To determine if $\mathrm{DC}_{\mathrm{TEX}-\mathrm{N} 1 \mathrm{ND}}$ has a direct impact on memory $\mathrm{T}$ cells, we immunized C57BL/6 mice with $\mathrm{DC}_{\mathrm{TEX}}$ $\left(2 \times 10^{6}\right)$ weekly for 3 weeks and harvested splenic $\mathrm{T}_{\mathrm{EM}}$ and $\mathrm{T}_{\mathrm{CM}}$ cells 4 weeks after the last immunization and stimulated $3 \times 10^{5}$ of each with $\mathrm{DC}_{\mathrm{TEX}-\mathrm{N} 1 \mathrm{ND}}$ or $\mathrm{DC}_{\mathrm{TEX}}\left(3 \times 10^{4}\right)$ for $72 \mathrm{~h}$. Stimulation of purified $\mathrm{T}_{\mathrm{CM}}$ by $\mathrm{DC}_{\mathrm{TEX}-\mathrm{N} 1 \mathrm{ND}}$ resulted in a dramatic increase in $\mathrm{T}_{\mathrm{CM}}$ and $\mathrm{T}_{\mathrm{EM}}$ numbers (Fig. 6a) and secreted IL-2 and IFN- $\gamma$ (Fig. 6b) compared with $\mathrm{DC}_{\mathrm{TEX}}$ treatment of controls, suggesting that $\mathrm{DC}_{\mathrm{TEX}-\mathrm{N} 1 \mathrm{ND}}$ enables efficient $\mathrm{T}_{\mathrm{CM}}$ proliferation and differentiation to $\mathrm{T}_{\mathrm{EM}}$ in response to stimulation. In the purified $\mathrm{T}_{\mathrm{EM}}$ culture, $\mathrm{T}_{\mathrm{EM}}$ numbers and IFN- $\gamma$ significantly rose after DC $_{\text {TEX-N1ND }}$ treatment compared with other controls (Fig. 6c), indicating N1ND also triggered robust $\mathrm{T}_{\mathrm{EM}}$ cell proliferation. To assess the direct impact of $\mathrm{DC}_{\mathrm{TEX}-\mathrm{N} 1 \mathrm{ND}}$ on naive $\mathrm{T}$ cells, we incubated $\mathrm{DC}_{\mathrm{TEX}-\mathrm{N} 1 \mathrm{ND}}$ or $\mathrm{DC}_{\mathrm{TEX}}$ with naive $\mathrm{T}$ cells for 3 or 6 days. Effector T cells and IFN- $\gamma$ were significantly elevated in $\mathrm{DC}_{\mathrm{TEX}-\mathrm{N}_{1 N D^{-}}}$and $\mathrm{DC}_{\mathrm{TEX}}$-treated naive $\mathrm{T}$ cells, though to a lesser extent with $\mathrm{DC}_{\mathrm{TEX}}$, compared with untreated $\mathrm{T}$ cell controls (Fig. 6d). Examination of memory T cells on day 3 and 6 revealed significantly increased memory $\mathrm{T}$ cells in $\mathrm{DC}_{\mathrm{TEX}-\mathrm{N} 1 \mathrm{ND}}$, compared with the controls (Fig. 6e), indicating that $\mathrm{DC}_{\mathrm{TEX}-\mathrm{N} 1 \mathrm{ND}}$ promotes accelerated generation of effector $\mathrm{T}$ cells early on which then promotes the differentiation of memory $\mathrm{T}$ cells. These findings demonstrate that $\mathrm{DC}_{\mathrm{TEX}-\mathrm{N} 1 \mathrm{ND}}$ augments generation of effector and memory $\mathrm{T}$ cells and results in amplification of immunological memory.

Migration of DC to regional lymph nodes, a function of DC activation, is a critical factor influencing therapeutic outcomes of DC vaccines ${ }^{26,27}$. To examine TEX-N1ND's effect on exogenous DC migration to lymph nodes, we tracked the tissue distribution of DiI-labeled DCs $\left(5 \times 10^{6}\right)$ in tumor-bearing mice $48 \mathrm{~h}$ after single intravenous injection. IVIS analysis (Fig. 6f) and flow cytometry of extracted tissues (Fig. $6 \mathrm{~g}$ and Supplementary Fig. 6) indicated more DCs migrated to the tumor and secondary lymphoid tissues including spleen, mesenteric, and inguinal lymph nodes in $\mathrm{DC}_{\mathrm{TEX}-\mathrm{N} 1 \mathrm{ND}}$-treated mice compared with $\mathrm{DC}_{\mathrm{TEX}}$ and controls. These findings strengthen the conclusion that TEXN1ND endows DCs with stronger immunogenicity and homing capacity to lymph nodes and results in boosted generation of effector and memory $\mathrm{T}$ cells, which accounts for the long-lasting antitumor immunity.

Since HMGN1 was known to function through toll-like receptor 4 (TLR4) $)^{12}$, TLR4-dependent signaling pathway was examined. Expression of TLR4, tumor necrosis factor receptorassociated factor 6 (TRAF6) and myeloid differentiation primary response gene 88 (MYD88) were upregulated in $\mathrm{DC}_{\mathrm{TEX}}$ and further enhanced by the presence of N1ND ( $\mathrm{DC}_{\mathrm{TEX}-\mathrm{N} 1 \mathrm{ND}}$ ) compared with DC alone (Supplementary Fig. 7a). Depletion of TLR4 and TRAF6 with CRISPR-Cas9 system (Supplementary Fig. 7b) generated TLR4 ${ }^{-1-}$ and TRAF6 ${ }^{-/-}$DCs. The knockouts obliterated upregulation of MHC I/II, co-stimulatory molecules (Supplementary Fig. 7c, d) and secreted proinflammatory cytokines TNF- $\alpha$ and IL-12 ${ }^{12}$ (Supplementary Fig. 7e) conferred by N1ND (TEX-N1ND vs. TEX) but did not affect upregulation associated with TEX (TEX vs. PBS controls). This suggests that TLR4 signaling pathway contributes to N1ND-mediated augmentation of DC activation, but not initial DC activation by TEX. The results firmly link TLR4 signaling to N1ND-mediated DC activation.

N1ND-painted patient serum exosomes augment DC immunity. It was reported that HMGN1 expression levels are inversely correlated to clinical stage of tumor in cancer patients such as breast and non-small cell lung carcinoma ${ }^{28}$. HCC patient tumors expressed less HMGN1 than para-tumoral tissues, which was inversely correlated to the expression of HCC-specific antigen AFP (Supplementary Fig. 8a). Consistently, HCC patient serum exosomes contained significantly less HMGN1 than exosomes from normal volunteers' serum (Fig. 7a, b), whereas AFP was up to eightfold higher (Fig. $7 \mathrm{~b}$ ). To determine the applicability of TEX-N1ND in the human setting, we loaded N1NDmodified exosomes, derived from HCC patients' serum (TEXN1ND), into human DCs derived from healthy volunteers'

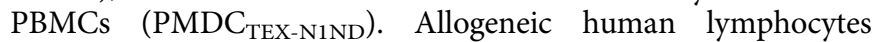


a

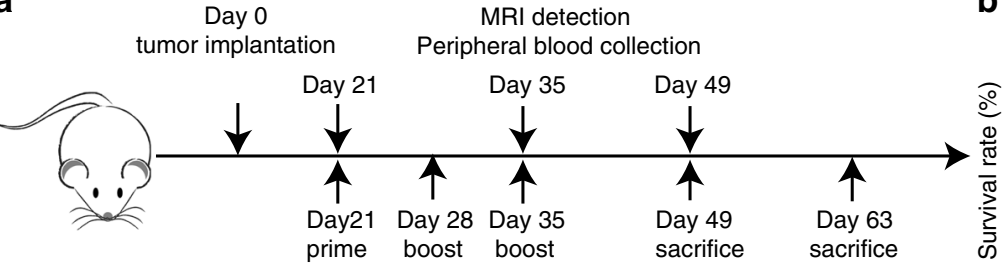

C
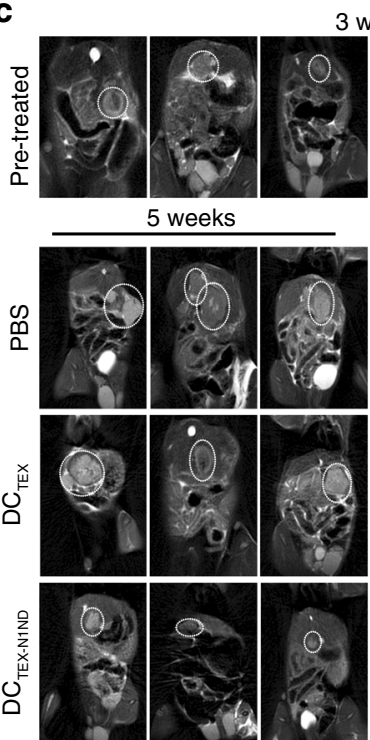

d
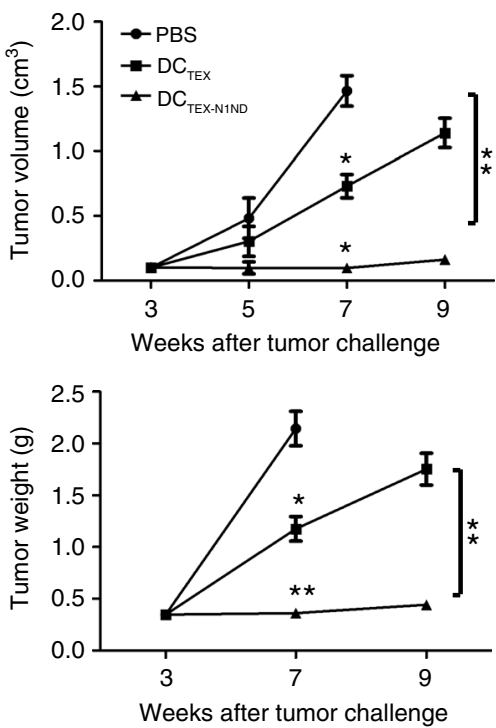

b
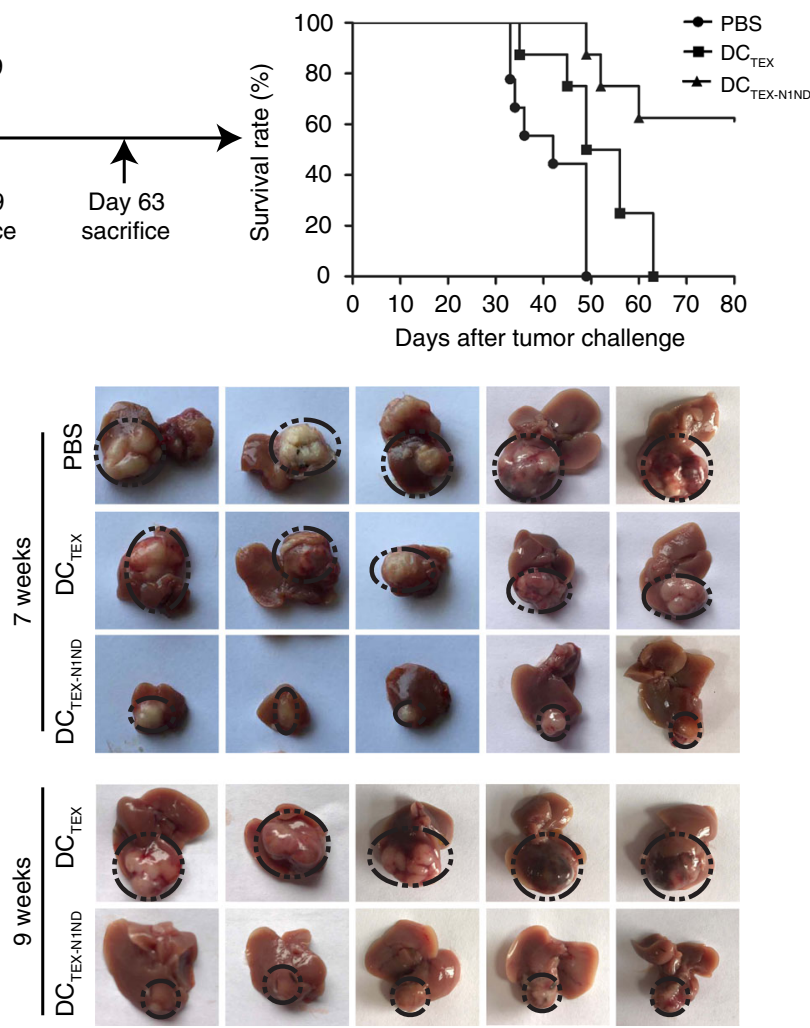

e PBS

$\mathrm{DC}_{\mathrm{TEX}}$

$D C_{\text {TEX-N1ND }}$
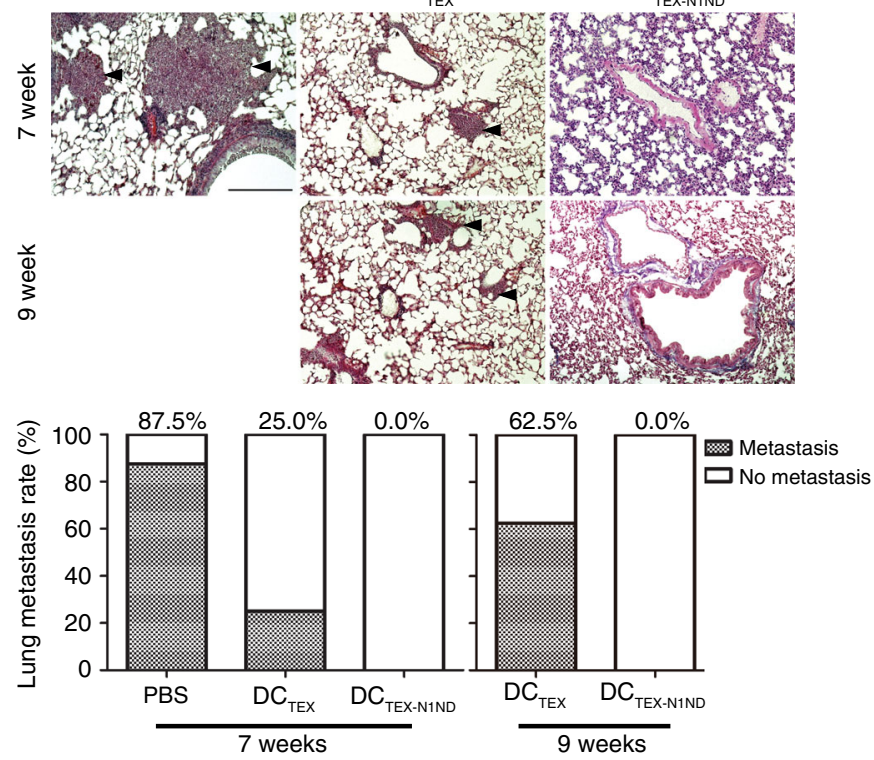

Fig. 3 Antitumor effect of $\mathbf{D C}_{\text {TEX-N1ND }}$ in orthotopic HCC mice $\mathbf{( H - 2}^{\mathbf{b}}$ ). Day-21 orthotopic C57BL6 HCC mice were intravenously treated with PBS(black

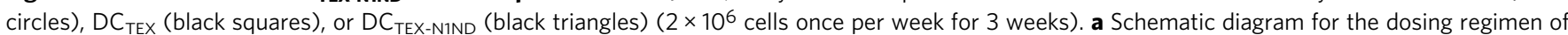
$\mathrm{DC}_{\text {TEX-N1ND }}$ in day-21 orthotopic C57BL/6 HCC mice therapeutically. b Survival rate of day-21 orthotopic HCC mice treated with PBS $(n=9), \mathrm{DC}$ TEX $(n=8)$, or $\mathrm{DC}_{\text {TEX-N1ND }}(n=8)$, respectively. c Real-time MRI monitoring and measurement of tumor nodules in day-21 orthotopic HCC mice treated with PBS, $\mathrm{DC}_{\mathrm{TEX}}$ or $\mathrm{DC}_{\mathrm{TEX}-\mathrm{N} 1 \mathrm{ND}}$ at different time-points. $\mathbf{d}$ Analysis of tumor volume and weight from orthotopic HCC mice treated with PBS, DC week $5(n=3)$, week 7 ( $n=11$ for PBS; $n=12$ for DC TEX and DC TEX-N1ND; one-way ANOVA on ranks), and $9\left(n=11\right.$ for DC TEX $_{\text {and }} n=12$ for DC TEX-N1NDi two-tailed Mann-Whitney $U$ test) (for pretreated controls on week $3, n=7$ ). The experiments for week 7 and 9 were repeated once (two in total). e Histological examination and quantitative analysis of pulmonary metastasis of HCC in lungs from orthotopic HCC mice treated with PBS, DC $D C_{\text {TEX-N1ND }}$ on week 7 and 9, respectively (scale bar $\left.=200 \mu \mathrm{m}\right)(n=8)$. Arrowheads point to HCC nodules. Data are presented as means \pm s.e.m. $\left({ }^{\star} p<\right.$ $\left.0.05 ;{ }^{\star \star} p<0.001\right)$. Source data are provided as a Source Data file. 
a

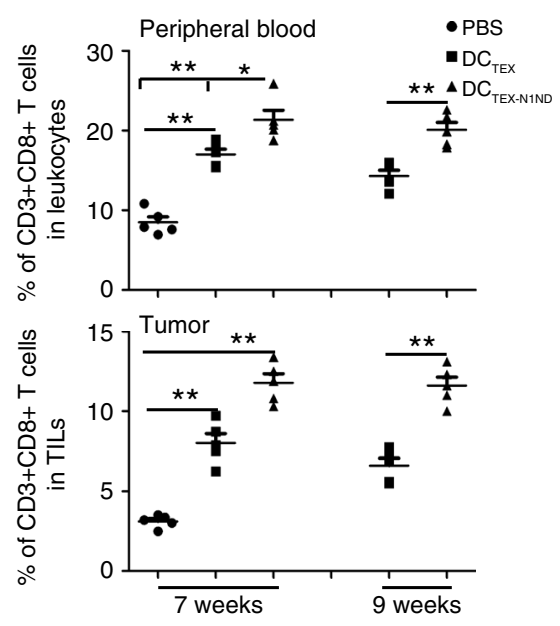

b

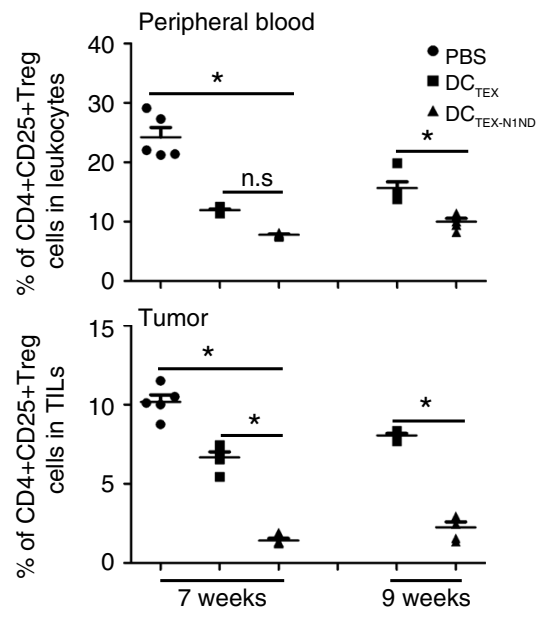

d
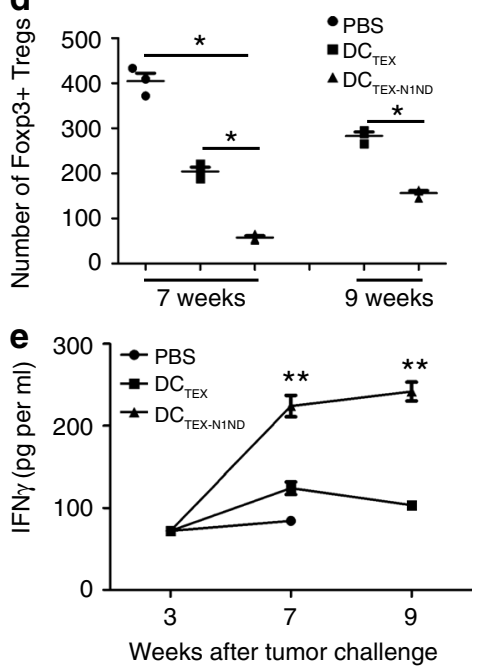

C

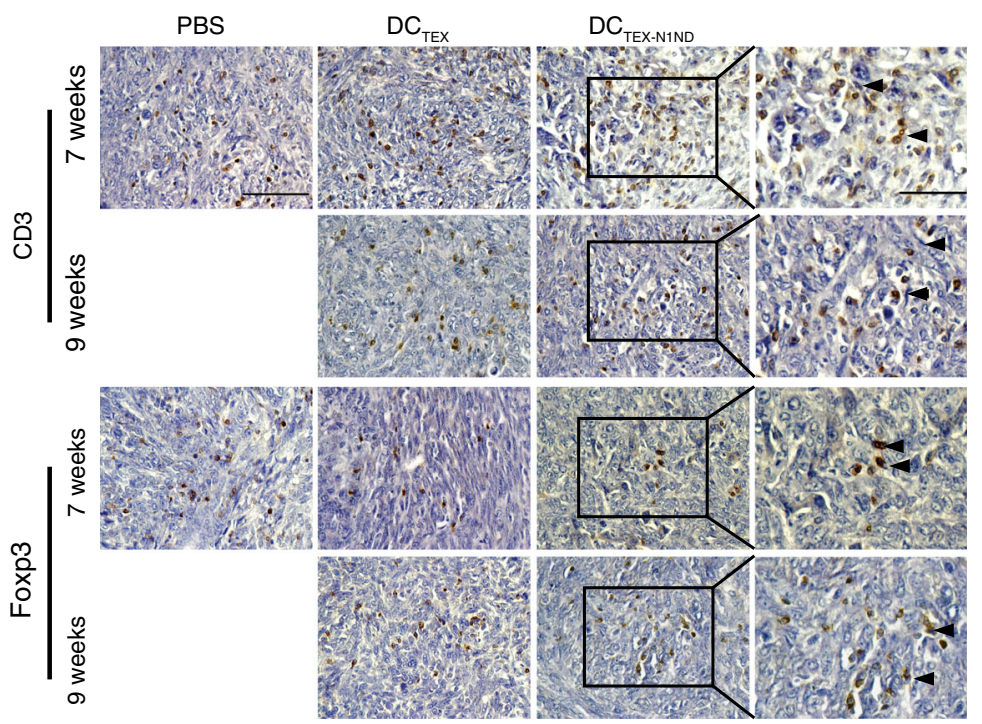

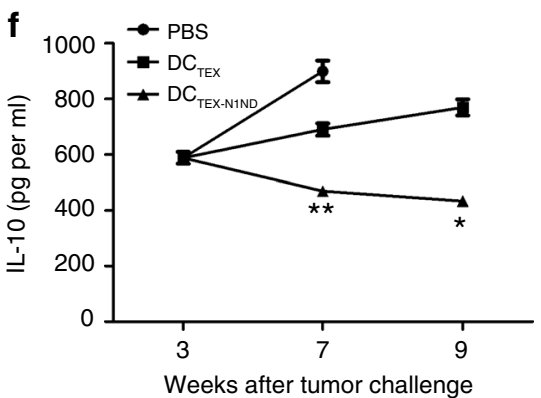

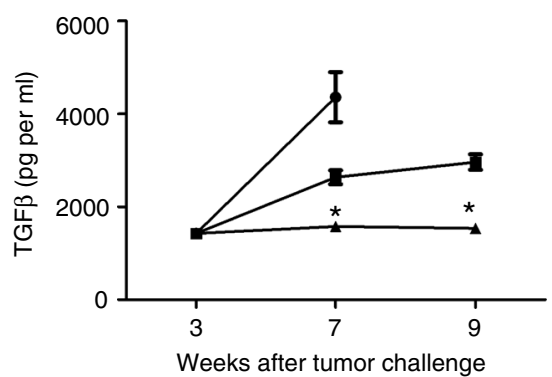

Fig. 4 DC $_{\text {TEX-N1ND }}$ reshaped orthotopic microenvironment in mice. a Flow cytometric analysis of CD8 ${ }^{+} \mathrm{T}$ lymphocytes in blood and tumor tissues from orthotopic C57BL/6 HCC mice treated with PBS, DC TEX, or DC TEX-N1ND on week 7 (one-way ANOVA post hoc Student-Newman-Keuls test) and 9 (twotailed $t$ test) $(n=5)$. b Flow cytometric analysis of $C D 4^{+}$CD25+ Tregs in blood and tumor tissues from orthotopic C57BL/6 HCC mice treated with PBS, $\mathrm{DC}_{\mathrm{TEX}}$, or DC $\mathrm{TEX}_{\mathrm{TENND}}$ on week 7 (one-way ANOVA on ranks) and 9 (two-tailed $t$ test) $(n=5)$. c Immunohistochemistry of $\mathrm{CD} 3^{+} \mathrm{T}$ cells and Foxp3 $3^{+}$Tregs in tumor sections from different treatment samples to determine the extent of T cell infiltration (scale bar $=100$ or $50 \mu \mathrm{m}$ in magnified images).

Arrowheads point to $\mathrm{CD}^{+}$or Foxp3 ${ }^{+} \mathrm{T}$ cells. This experiment was repeated once (two in total). $\mathbf{d}$ Quantification of Foxp3 ${ }^{+} \mathrm{T}$ cells in tumor sections from different treatment groups on week 7 (one-way ANOVA on ranks) and 9 (two-tailed Mann-Whitney $U$ test) $(n=3 ; n$ represents the number of animals used for each group). e Measurement of IFN- $\gamma$ in tumor tissues from treated mice with ELISA on week $3(n=3)$, week 7 ( $n=5$; one-way ANOVA post hoc Student-Newman-Keuls test), and $9(n=5$; two-tailed $t$ test). $\mathbf{f}$ Measurement of immunosuppressive cytokines including TGF- $\beta$ on week 3 ( $n=3$ ), week 7 (one-way ANOVA on ranks), and 9 (two-tailed Mann-Whitney $U$ test) $(n=5)$ and IL-10 on week $3(n=3), 7$ ( $n=5$; one-way ANOVA post hoc Student-Newman-Keuls test), and 9 ( $n=5$; two-tailed Mann-Whitney $U$ test). $N$ represents the number of animals used for each group. The comparison was conducted between $D C_{\text {TEX-N1ND }}$ and DC $C_{\text {TEX }}$ or PBS groups at the same time-point. Data are presented as means \pm s.e.m. ${ }^{*} p<0.05$; ${ }^{* \star} p<0.001$; n.s not significant). Source data are provided as a Source Data file.

activated by $\mathrm{PMDC}_{\mathrm{TEX}-\mathrm{N} 1 \mathrm{ND}}$ resulted in significantly higher tumor-specific cytolysis rates against different human HCC cells than counterparts activated by $\mathrm{PMDC}_{\mathrm{TEX}}$ or $\mathrm{PMDC}$ and unprimed lymphocytes irrespective of the origin of HCC cells (Figs. 7c and Supplementary Fig. 8b). Likewise, HMGN1 expression was reduced in exosomes from pancreatic and breast cancer patients' serum compared with normal volunteers (Supplementary Fig. 8c, d). To explore the general applicability of $\mathrm{N} 1 \mathrm{ND}$ as an immunoadjuvant in the clinic, we painted exosomes from pancreatic and breast cancer patients' serum and loaded

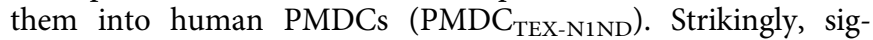
nificantly higher cytolysis rates against pancreatic and breast cancer patient cells were detected in lymphocytes stimulated by PMDC $_{\text {TEX-N1ND }}$ compared with corresponding $\mathrm{PMDC}_{\mathrm{TEX}}$ or unprimed lymphocytes (Fig. $7 \mathrm{~d}$ ). The data demonstrate that N1ND can augment human DC immunogenicity in vitro in the presence of tumor-specific antigen and thus provide an avenue for improving DC vaccines. 
a

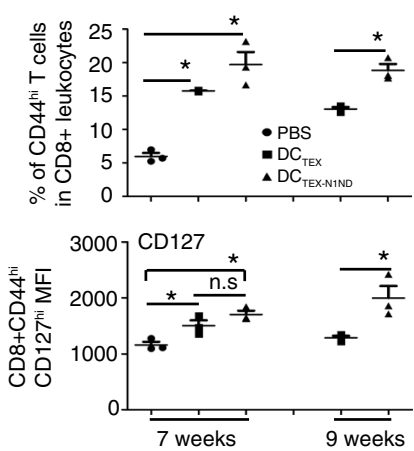

d
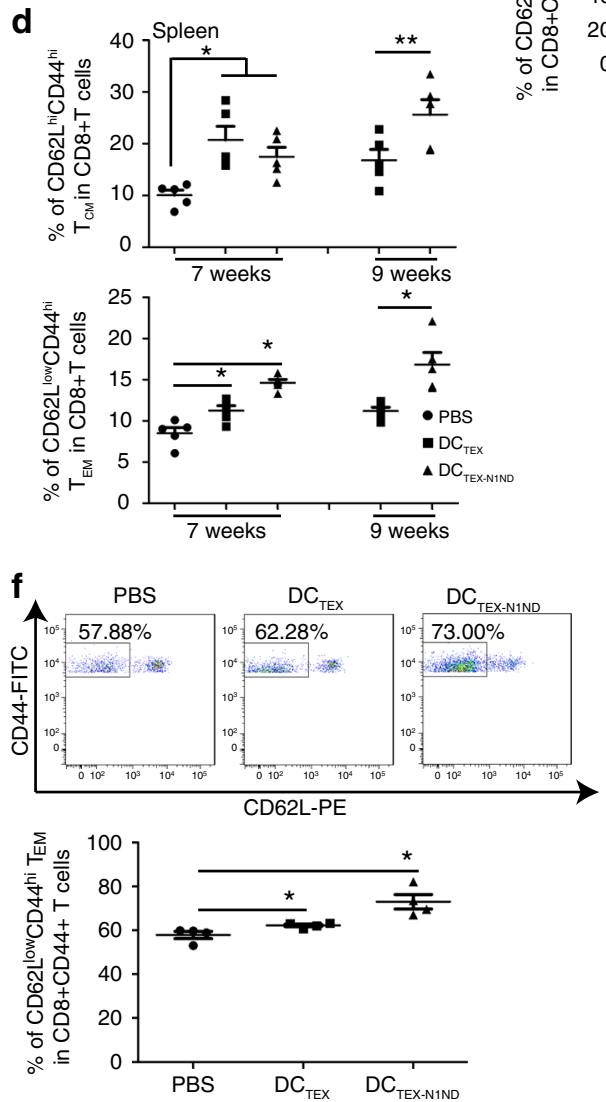

g

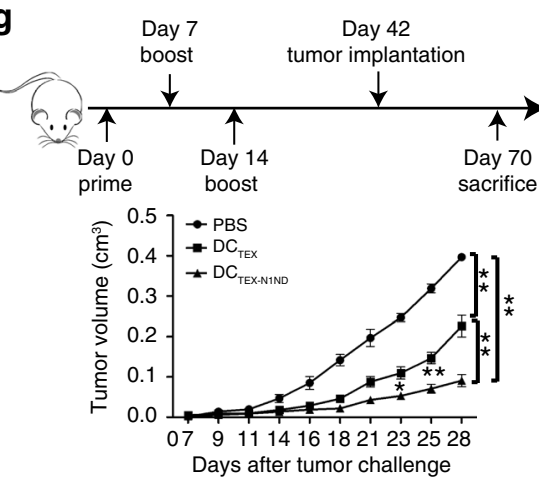

\section{Discussion}

It remains challenging to induce robust, durable antitumor immune response capable of markedly prolonging patient survival against large, poorly immunogenic tumors. Although DC vaccines show promises in the clinic with great safety profiles, limited clinical success has been achieved in treating large b
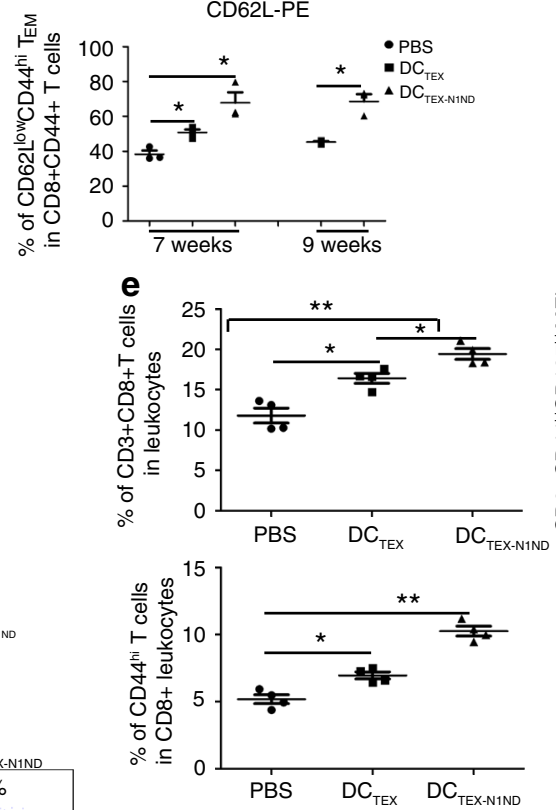

h
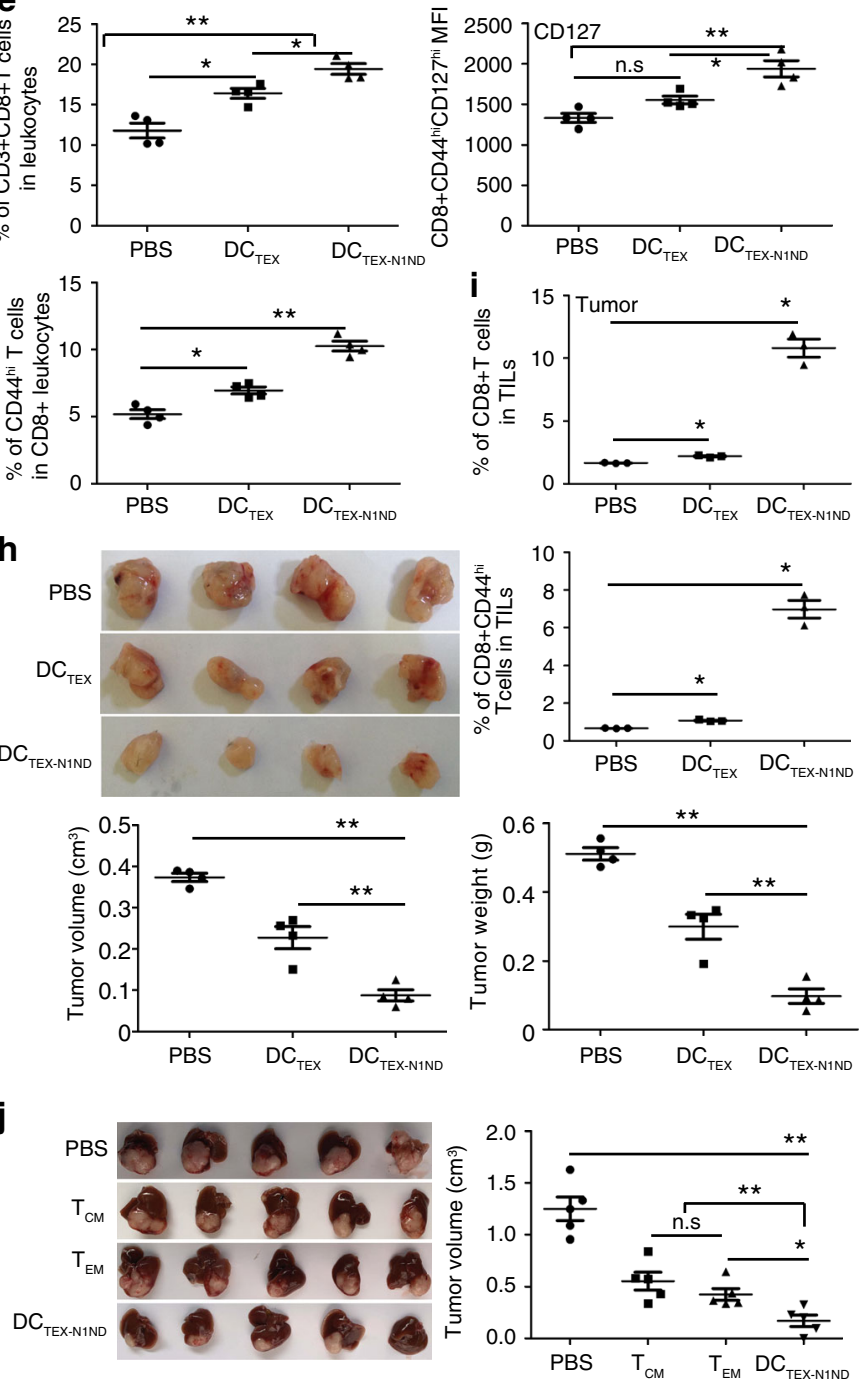
Fig. 5 DC $_{\text {TEX-Nind }}$ augmented memory T cells in orthotopic HCC mice. Flow cytometric analysis of long-lived memory $T$ cells (a) or $T_{E M}$ cells (b) in blood from day-21 orthotopic HCC mice treated with DC TEX-N1ND, $_{\text {DC }}$ TEX or PBS on week 7 (one-way ANOVA on ranks) and 9 (two-tailed $t$ test). CD44 ${ }^{\text {hi }}$ or CD127hi means CD44high or CD127high, respectively $(n=3)$. MFI mean fluorescence intensity. Quantitative analysis of long-lived memory T cells (c) or $T_{E M}$ and $T_{C M}$ cells $(\mathbf{d})$ in the spleen from day-21 orthotopic HCC mice treated with DC TEX-N1ND, $_{\text {DC }}$ TEX, or PBS on week 7 (one-way ANOVA post hoc Student-Newman-Keuls test) and 9 (two-tailed $t$ test), respectively $(n=5)$. CD62 Li represents CD62L high. Flow cytometric analysis of effector and memory $\mathrm{T}$ cells $(\mathbf{e})$ or $\mathrm{T}_{\mathrm{EM}}$ cells (f) in blood from immunized wild-type C57BL/6 mice before tumor challenge (one-way ANOVA post hoc Student-Newman-Keuls test). These mice were immunized intravenously with $\mathrm{DC}_{\text {TEX-N1ND, }} \mathrm{DC}_{\mathrm{TEX}}\left(2 \times 10^{6}\right.$ cells once per week for 3 weeks $)$ or PBS, respectively and blood was collected 4 weeks after last immunization before challenge $(n=4)$. Measurement of tumor growth (g) or tumor volume/ weight (h) of immunized C57BL/6 mice at 4 weeks after challenge $(n=4$; one-way ANOVA post hoc Student-Newman-Keuls test). i Flow cytometric analysis of effector and memory T cells in tumor tissues from C57BL/6 mice immunized with DC TEX $_{\text {or DC }}$ TEX-N1ND 4 weeks after tumor challenge $(n=3$; one-way ANOVA on ranks). TILs refer to tumor-infiltrating lymphocytes. $\mathbf{j}$ Measurement of tumor growth of day-7 established orthotopic HCC mice

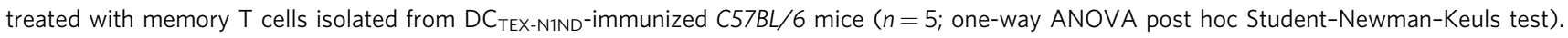
$D C_{\text {TEX-N1ND }}$ was used as a positive control. Data are presented as means \pm s.e.m. $\left({ }^{\star} p<0.05 ;{ }^{\star \star} p<0.001 ;\right.$ n.s not significant). Source data are provided as a Source Data file.

pathways or checkpoint inhibitors ${ }^{13-15}$, but the effective delivery of HMGN1 to tumors has confounded researchers. Here we described a simple and effective approach to load the potent N1ND immunoadjuvant on TEXs via an exosomal anchor peptide (TEX-N1ND), resulting in efficient delivery of N1ND to DCs together with TAAs. TEX-N1ND dramatically enhances DCs' antitumor immunity by improving DC activation, homing capacity to lymph nodes and the generation and amplification of long-lasting memory $\mathrm{T}$ cells. Memory $\mathrm{T}$ cells consequently contribute to robust and persistent tumor regression in mice bearing large established tumors. Strikingly, the amplified immunogenicity of DCs triggered by TEX-N1ND yielded prolonged tumor regression and persistent antitumor immune response, and also reshaped the immune and tumor microenvironment in mice with poorly immunogenic orthotopic large HCCs. This is particularly important for HCC as it is notorious for highly immunosuppressive tumor microenvironment which facilitates tumor evasion of the immune system ${ }^{29}$. Notably, TEX-N1ND could trigger a greater antitumor immunity of DCs if only CD63-positive TEXs were used. However, given the cost and efforts required for doing so, it might not be a worthwhile trade-off. Furthermore, TEXN1ND enabled the augmentation of human DCs' immunogenicity irrespective of the endogenous expression level of HMGN1 in or origins of TEXs, demonstrating the clinical and general applicability of N1ND as an immunoadjuvant in DC-based immunotherapy. This is the first study, to our knowledge, to demonstrate the potency of N1ND as an immunoadjuvant and a simple approach to load TEXs with various cargoes for delivery and thus our study provides a platform to augment antitumor immunity induced by DC vaccines.

In our current study, although tumor growth was significantly inhibited with $\mathrm{DC}_{\mathrm{TEX}-\mathrm{N} 1 \mathrm{ND}}$ in different mouse models bearing large tumor loads, all the mice still succumbed to tumor, underlining the tenacity of large established tumors at overcoming current therapeutics. Nevertheless, long-lasting antitumor immunity was established in both subcutaneous and orthotopic tumor mouse models, which remarkably prevented tumor progression and lung metastasis, two crucial outcomes that can lead to prolonged quality-adjusted survival in patients with a large tumor burden. The reduction in tumor size may also allow surgical intervention that would have been previously impossible. Further optimization including the delivery route and dosing regimens and long-term efficacy will be investigated in our future studies. Notably, both DC cell line (DC2.4) and the more clinically acceptable bone marrow (BM)-derived primary DCs were tested in our study and similar cellular uptake efficiency and immunogenicity were observed when DCs were pulsed with TEXN1ND under an identical protocol, indicating the source of DCs has no impact on the potency of N1ND and TEXs. However, considering that the low yield of BMDC limits its scale-up, particularly for in vivo studies, we used DC cell line for subsequent orthotopic studies. Perhaps as a positive, we believe that we are moderately successful at shifting the bottleneck of DC immunotherapy from the lack of immunostimulation to production of sufficient numbers of DC for therapy, which can be considered a significant progress in this field.

HMGN1 was chosen in our study as it can recruit and activate not only DCs but also NK cells, neutrophils, and monocytes/ macrophages $12,13,30$. The truncated N1ND fragment painted on TEX as expected was effective at DC activation, which consequently boosted $\mathrm{CD}^{+} \mathrm{T}$ cells. Also significantly increased numbers of memory $\mathrm{T}$ cells were induced by $\mathrm{DC}_{\mathrm{TEX}-\mathrm{N} 1 \mathrm{ND}}$, which largely contribute to the long-lasting antitumor immunity. Notably, the increase in memory $\mathrm{T}$ cells induced by $\mathrm{DC}_{\mathrm{TEX}-\mathrm{N} 1 \mathrm{ND}}$ over $\mathrm{DC}_{\mathrm{TEX}}$ in blood was mainly in the number of effector memory $\mathrm{T}$ cells rather than central memory $\mathrm{T}$ cells as evidenced by significantly elevated numbers of effector memory $\mathrm{T}$ cells and only a marginal increase in central memory $\mathrm{T}$ cells from $\mathrm{DC}_{\mathrm{TEX}}$ N1ND-treated group compared with $\mathrm{DC}_{\mathrm{TEX}}$. As expected, NK cells significantly increased in blood and tumor tissues from mice with large established tumors in three different tumor mouse models (Supplementary Fig. 9a), suggesting that there could be other non- $T$ cell innate immune effects related to the long-lasting antitumor immunity elicited by TEX-N1ND ${ }^{12}$. Nevertheless, T cell-specific immune responses are primarily responsible for the observed antitumor effect as there was no significant tumor inhibition detected in subcutaneous HCC-bearing thymus-deficient but NK-intact nude mice when treated with BMDC ${ }_{\text {TEX-N1ND }}$ (Supplementary Fig. 9b, c).

Interestingly, HMGN1 was reported to decline in advanced stages of breast and non-small cell lung cancer patients ${ }^{28}$, and is also likely to be the case for HCC and pancreatic cancer. We have indeed observed that HMGN1 expression is lowered in HCC tumor than para-tumoral tissues. In this study, we show that TEX-N1ND is effective irrespective of the endogenous HMGN1 expression in tumors and it seems that it works better in tumors with low HMGN1 expression, which is loosely correlated to staging of cancer. Furthermore, this DC vaccine can also be used in large poorly immunogenic tumors. Thus, we are hopeful that the patients who are going to benefit the most from this treatment modality are those with advanced cancers that do not respond to other therapies. Worthy of mentioning, a uniqueness of our study is that we demonstrated the ability to use cancer exosomes to deliver endogenous tumor antigens and exogenous cargoes (such as N1ND) by painting with $\mathrm{CP} 05$, and thus simplify the process of developing improved DC vaccines.

A difficulty to test our system in autochthonous HCC mouse models bearing large tumor burdens is that it is hard to control 
a

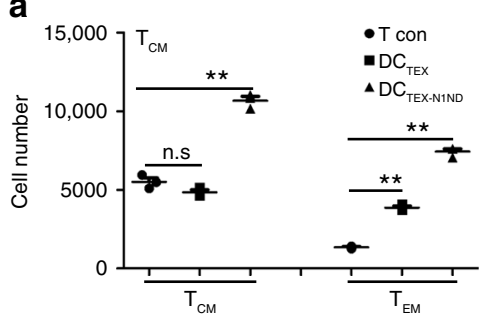

C
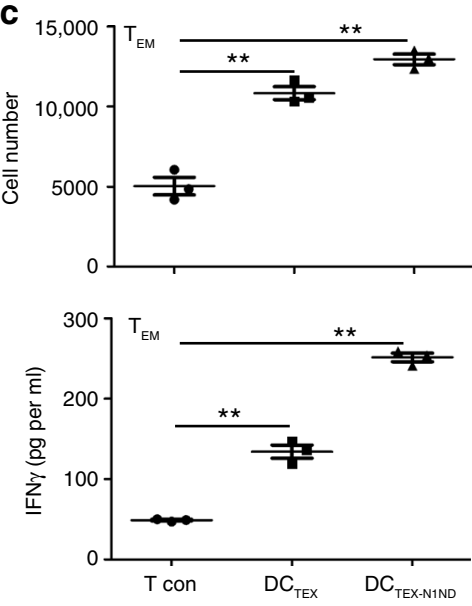

f
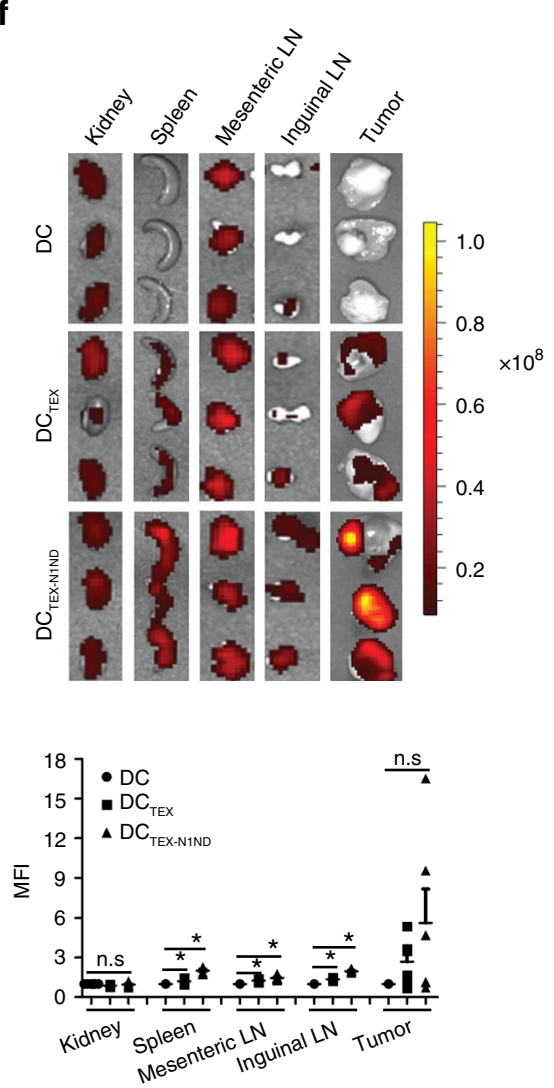

b
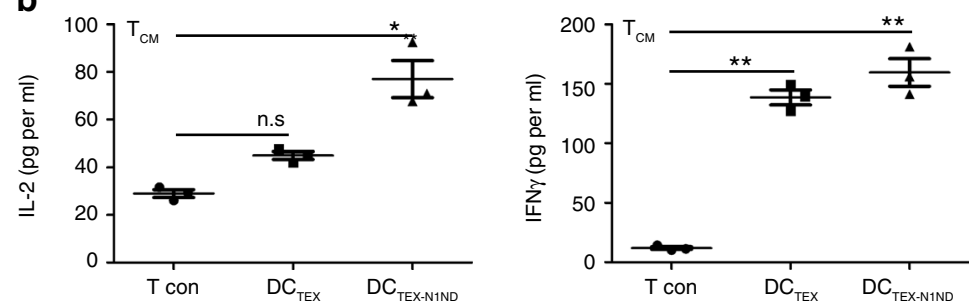

d
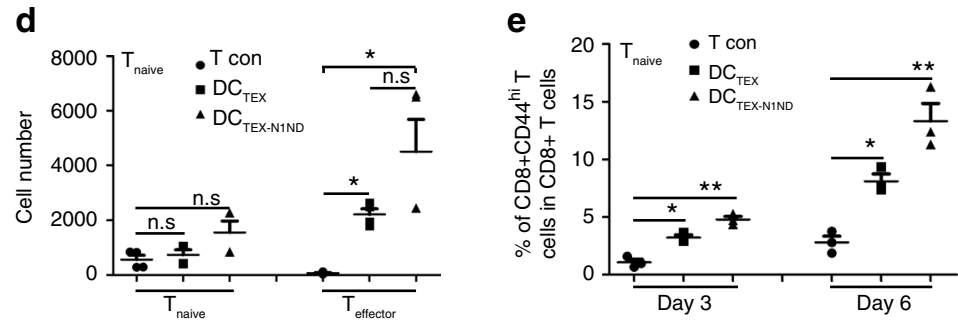
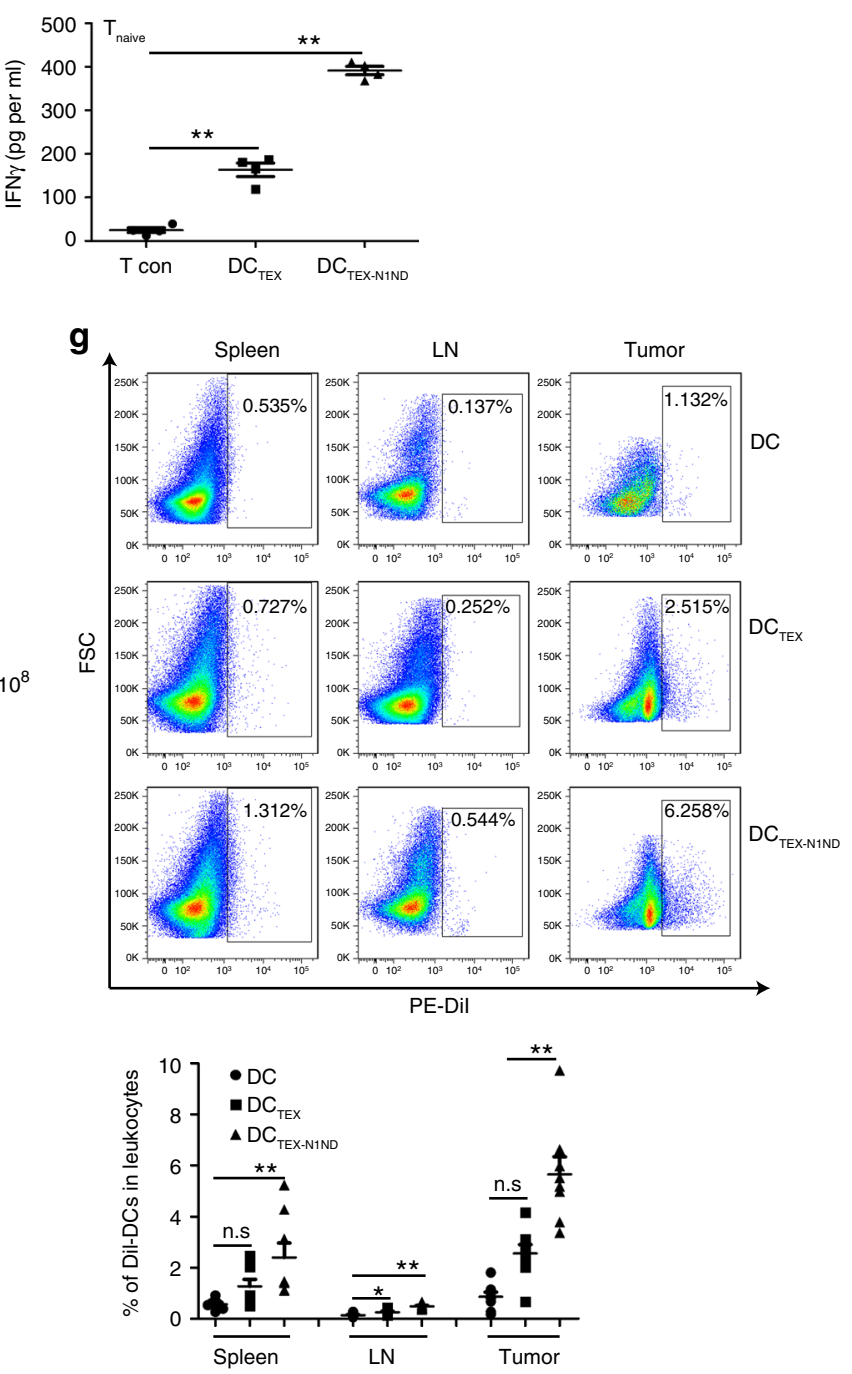

tumor size as multinodular, dispersed, and nonuniform tumors formed in carcinogen-induced autochthonous HCC mice ${ }^{31}$. In order to closely evaluate the immunosuppressive nature of local tumor immune microenvironment manifested in late-stage HCC patients, we transplanted fewer tumor tissues to allow the establishment of immunosuppressive microenvironment in orthotopic HCC mice as demonstrated by significantly increased numbers of immunosuppressive Tregs and elevated levels of TGF- $\beta$ in blood and tumor tissues from day-21 orthotopic HCC mice compared with normal controls (Supplementary Fig. 3a). 
Fig. 6 Effect of DC $\mathbf{D C}_{\text {TEX-N1ND }}$ on T cells from DC $\mathbf{C}_{\text {TEX-N1ND-immunized mice. } C 57 B L / 6 \text { mice were immunized with } \mathrm{DC} \text { TEX-N1ND }}\left(2 \times 10^{6}\right.$ cells once per week for 3 weeks) and splenic memory or naive $T$ cells were isolated from immunized mice 4 weeks after last immunization. a Quantification of $T_{C M}$ and $T_{E M}$ cells in $\mathrm{T}_{\mathrm{CM}}$ cell populations after the co-incubation of $\mathrm{T}_{\mathrm{CM}}$ cells with $\mathrm{DC}_{\mathrm{TEX}-\mathrm{N} 1 \mathrm{ND}}$ or $\mathrm{DC}_{\mathrm{TEX}}\left(3 \times 10^{4}\right)$ for 3 days $(n=3$; one-way ANOVA post hoc

Student-Newman-Keuls test; $n$ represents the number of animals immunized with DC $C_{\text {TEX-NIND }}$ ). $\mathbf{b}$ Levels of IFN- $\gamma$ and IL- 2 in the culture medium after the co-incubation of $\mathrm{T}_{\mathrm{CM}}$ cells with $\mathrm{DC}_{\mathrm{TEX}-\mathrm{N} 1 \mathrm{ND}}$ or $\mathrm{DC}_{\mathrm{TEX}}\left(3 \times 10^{4}\right)$ for 3 days $(n=3$; one-way ANOVA post hoc Student-Newman-Keuls test; $n$ represents the number of animals immunized with $\mathrm{DC}_{\text {TEX-N1ND }}$ ). $\mathrm{c}$ Analysis of $\mathrm{T}_{\mathrm{EM}}$ cells and IFN- $\gamma$ in $\mathrm{T}_{\mathrm{EM}}$ cell populations stimulated with $\mathrm{DC} \mathrm{C}_{\mathrm{TEX}-\mathrm{N} 1 \mathrm{ND}}$ or $\mathrm{DC}$ TEX $\left(3 \times 10^{4}\right)$, respectively ( $n=3$; one-way ANOVA post hoc Student-Newman-Keuls test; $n$ represents the number of animals immunized with DC of effector T cells (one-way ANOVA on ranks) and IFN- $\gamma$ (one-way ANOVA post hoc Student-Newman-Keuls test) in naive T cell populations stimulated with $\mathrm{DC}_{\text {TEX-N1ND }}$ or $\mathrm{DC}_{\mathrm{TEX}}\left(3 \times 10^{4}\right)$ for 3 or 6 days, respectively $(n=4 ; n$ represents the number of animals used for isolation of naive T cells). e Quantification of memory $T$ cells in naive T cell populations after the co-incubation of naive T cells with DC TEX-N1ND or DC TEX $\left(3 \times 10^{4}\right)$ on day 3 and 6 , respectively ( $n=3$; one-way ANOVA post hoc Student-Newman-Keuls test; $n$ represents the number of animals used for isolation of naive T cells). $\mathbf{f}$ Tissue distribution and quantification of Dil-labeled $\mathrm{DC}_{\mathrm{TEX}-\mathrm{N} 1 \mathrm{ND}}$ or $\mathrm{DC}_{\mathrm{TEX}}\left(5 \times 10^{6}\right)$ in orthotopic HCC mice $48 \mathrm{~h}$ after single intravenous injection $(n=6$; one-way ANOVA on ranks). The ratio is relative to untreated DCs. LN lymph node. $\mathbf{g}$ Flow cytometric analysis of Dil-labeled DC orthotopic HCC mice $48 \mathrm{~h}$ after single intravenous injection ( $n=8$; one-way ANOVA post hoc Student-Newman-Keuls test). These experiments were repeated once (two in total). Data are presented as means \pm s.e.m. $\left({ }^{\star} p<0.05 ;{ }^{\star \star} p<0.001 ;\right.$ n.s not significant). Source data are provided as a Source Data file.
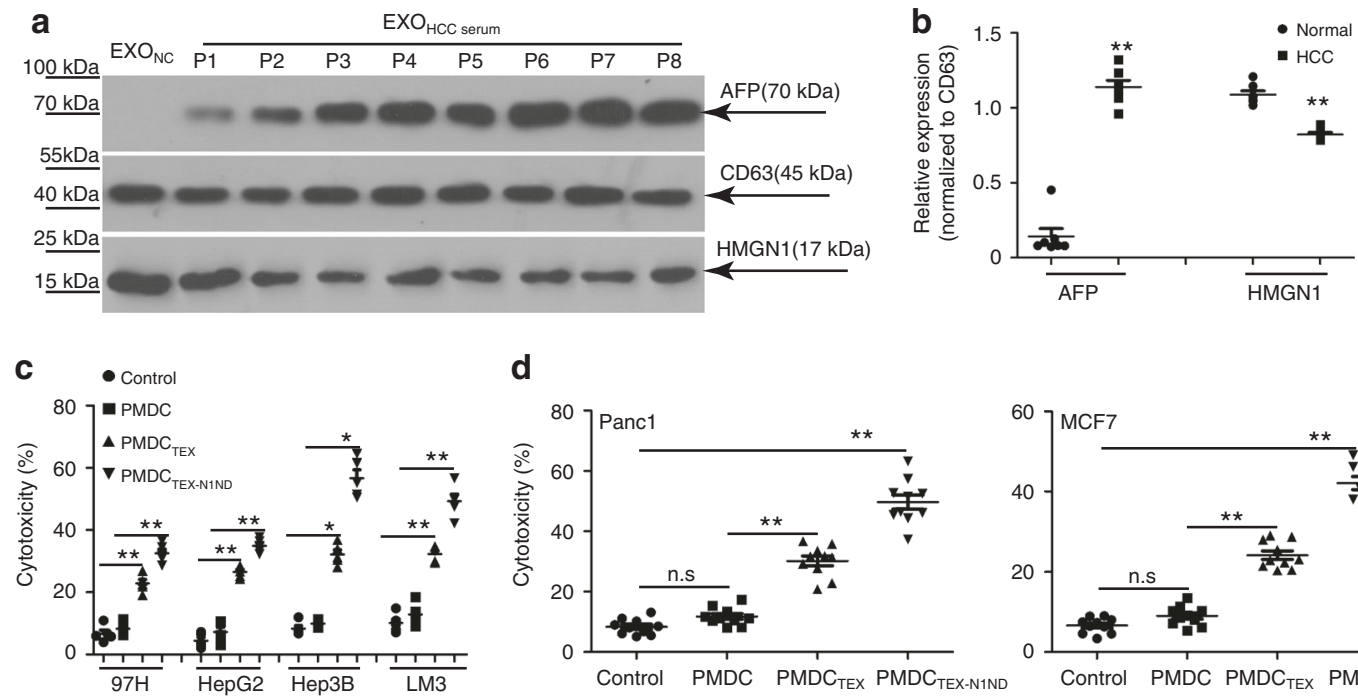

d
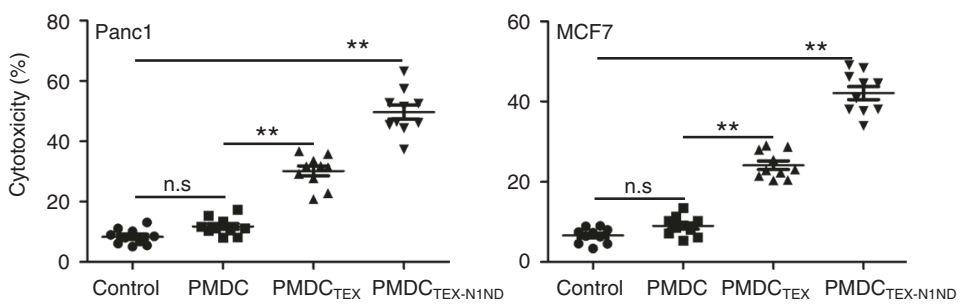

Fig. 7 TEX-N1ND augmented human DC immunity. a Western blot analysis for detecting the levels of HMGN1 and AFP expression in serum exosomes derived from normal healthy volunteers and HCC patients. Total protein ( $20 \mu \mathrm{g})$ was loaded and CD63 was used as an exosomal marker protein. This experiment was repeated once (two in total). $\mathbf{b}$ Quantitative analysis of levels of HMGN1 (two-tailed $t$ test) and AFP (two-tailed Mann-Whitney $U$ test) in serum exosomes derived from normal healthy volunteers $(n=7)$ and HCC patients $(n=8)$. c Cytolysis rate against different human HCC cells with

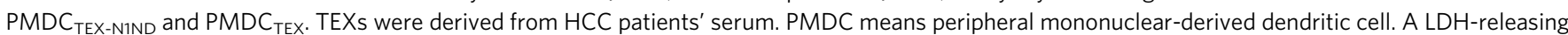
cytotoxic assay was performed to measure the cytolysis efficiency of effector lymphocytes activated by PMDC TEX-N1ND $_{\text {or PMDC }}$ TEX, respectively $(n=5$; one-way ANOVA post hoc Student-Newman-Keuls test except for Hep3B in which one-way ANOVA on ranks was used). Control refers to human PBMCderived lymphocytes. d Cytolysis rate against human pancreatic and breast cancer cells with PMDC pancreatic or breast cancer patients' serum, respectively ( $n=10$; one-way ANOVA on ranks). These experiments were repeated once (two in total). Data are presented as means \pm s.e.m. $\left({ }^{\star} p<0.05 ;{ }^{\star \star} p<0.001 ;\right.$ n.s not significant). Source data are provided as a Source Data file.

Therefore, as a proof-of-concept study, orthotopic HCC transplantation models were used. However, further long-term investigation of $\mathrm{DC}_{\text {TEX-N1ND }}$ will be undertaken in diethylnitrosamineinduced autochthonous HCC models after optimization of treatment doses and kinetics.

Taken together, our study demonstrates a simple and direct approach to efficiently load cargoes for TEX, as well as the potency of N1ND in augmenting DC immunogenicity by promoting DC activation, homing capacity to lymph nodes and thus accelerating the generation of long-lasting memory $\mathrm{T}$ cells. This in turn contributes to the robust and persistent antitumor immunity in large established tumors in mice and human cell in vitro. Our study provides a platform for amplifying the antitumor immunity of DC vaccines and thus accelerates the development of DC-based immunotherapy.

\section{Methods}

Mice. $C 57 B L / 6$ wild-type $\left(\mathrm{H}-2^{\mathrm{b}}\right), B A L B / C$ mice $\left(\mathrm{H}-2^{\mathrm{d}}\right)$, and thymus-deficient $B A L B / C$ nude mice (6-8-week old) were used in all experiments (five mice were used in each group for ectopic or orthotopic studies unless otherwise specified). Mice were housed under specific pathogen-free conditions in a temperature- and humidity-controlled room. All the animal experiments were carried out in the animal unit, Tianjin Medical University (Tianjin, China) according to procedures authorized and specifically approved by the institutional ethical committee (Permit Number: SYXK 2009-0001). Mice were sacrificed by $\mathrm{CO}_{2}$ inhalation at desired time-points, and tissues were either snap-frozen in liquid nitrogen-cooled isopentane or fixed with Bouin's solution (Sigma, USA) and embedded with paraffin for histological study.

Cell lines. Murine DC line DC2.4 (referred to DC) $\left(\mathrm{H}-2^{\mathrm{b}}\right)$ (kindly provided by $\mathrm{Dr}$ De Yang, Center for Cancer Research, NIH, USA) was used for murine orthotopic HCC studies ${ }^{32}$. Briefly, DC cells were cultured in Dulbecco's modified Eagle's medium (DMEM) with $1 \%$ antibiotics, $1 \%$ glutamine (Gln), $50-\mu \mathrm{M} \beta$-mercaptoethanol, and $10 \%$ depleted fetal bovine serum (FBS, Hyclone, USA), obtained by 
centrifugation at $100,000 \mathrm{~g}$ for $1 \mathrm{~h}$ to remove possible FBS-containing exosomes. Murine HCC cell line Hepa1-6 (H-2 $\left.{ }^{b}\right)$ was purchased from Boster Biological Technology Ltd (Wuhan, China) and cultured in DMEM with 2-mM Gln and 10\% FBS as per manufacturer's instructions. Murine pancreatic cancer cell line (Panc02, $\mathrm{H}-2^{\mathrm{b}}$ ), Lewis lung cancer cell line (LLC1, H-2 ${ }^{\mathrm{b}}$ ), breast cancer cell line $\left(4 \mathrm{~T} 1, \mathrm{H}-\mathrm{2}^{\mathrm{d}}\right.$ ), cervical cancer cell (Hela), and lymphoma cell (EL4) were kept in house and cultured as previously described ${ }^{33,34}$. Human HCC cell lines including HepG2 and Hep3B (purchased from ATCC biobank) and MHCC-97H (purchased from Shanghai Institute for Biological Sciences, Chinese Academy of Sciences) and LM3 (purchased from BeNa Culture Collection, Beijing, China) and cultured as per manufacturer's instructions $s^{35}$. Human pancreatic cancer cell line (Panc1) and breast cancer cell line (MCF7) were purchased from ATCC biobank and cultured as per manufacturer's instructions. Briefly, cells were grown at $37^{\circ} \mathrm{C}$ in $5 \% \mathrm{CO}_{2}$ in DMEM supplemented with $10 \%$ FBS obtained by centrifugation at $100,000 \mathrm{~g}$ for $1 \mathrm{~h}$ to remove possible FBS-containing exosomes, and $1 \%$ penicillin and streptomycin.

Peptides. N1ND (HMGN1 $\left.1^{1-52}\right)^{12}$ and N1ND-CP05 were synthesized as a single fusion peptide via peptide bond without spacer by Chinapeptide (Suzhou, China) with $96 \%$ of purity and labeled with AF680 by Prof. Qibing Zhou's lab (Huazhong University of Science and Technology, Wuhan, China).

Establishment of ectopic and orthotopic tumor mouse models. Subcutaneous tumor mouse models bearing large tumor loads were established by subcutaneous injection of $0.1 \mathrm{ml}$ PBS containing Hepal-6 cells $\left(2 \times 10^{6}\right)$, Panc02 $\left(2 \times 10^{6}\right)$, and $4 \mathrm{~T} 1\left(2 \times 10^{6}\right)$ into left axilla of $C 57 B L / 6, B A L B / C$, or thymus-deficient $B A L B / C$ nude mice $\left(5 \times 10^{5}\right.$ of Hepa1- 6 cells) $(n=5,6-8$-week old) and allowed to grow for 14 days or 7 days (for nude mice). For the establishment of orthotopic HCC mice, subcutaneous tumors with a longitudinal diameter of $1 \mathrm{~cm}$ were peeled from subcutaneous mouse models after schedule 1 killing. Tumor tissues were washed in D-hanks buffer. Necrotic tissues were removed from tumors and tumor tissues were cut into about $1 \mathrm{~mm}^{3}$ pieces. Two to three tumor pieces were implanted in the left lobe of liver in the recipient mice under anesthesia. The length $(L)$ and width $(W)$ of tumors were measured with a caliper. Tumor size was calculated by the formula: $\left(L \times W^{2}\right) / 2^{18}$.

Isolation of murine DCs, human DCs, and lymphocytes. For murine in vitro studies, BM-derived DCs were generated as previously reported ${ }^{36}$. BM progenitors $\left(1 \times 10^{6}\right.$ cells per ml) isolated from BMs of $C 57 B L / 6$ or $B A L B / C$ mice were cultured in Roswell Park Memorial Institute (RPMI) 1640 medium plus 10\% FBS, 1\% P/S (100 $\mathrm{U} \mathrm{ml}^{-1}$ penicillin and $100 \mu \mathrm{g} \mathrm{ml}^{-1}$ streptomycin), murine granulocytemacrophage colony-stimulating factor (GM-CSF) $\left(200 \mathrm{U} \mathrm{ml}^{-1}\right)$ (PeproTech, USA) and interleukin-4 (IL-4) $\left(100 \mathrm{U} \mathrm{ml}^{-1}\right)$ (PeproTech, USA), and $50 \mu \mathrm{moll}^{-1} \beta$ mercaptoethanol at $37^{\circ} \mathrm{C}$ in a humidified incubator with $5 \% \mathrm{CO}_{2}$ for $5-7$ days to generate immature DCs. Subsequently, immature DCs $\left(1 \times 10^{6}\right.$ cells per $\left.\mathrm{ml}\right)$ were incubated in fresh culture medium in the absence or presence of TEX or N1NDCP05 modified TEX (TEX-N1ND) for $48 \mathrm{~h}$ at $37^{\circ} \mathrm{C}$ in a humidified incubator with $5 \% \mathrm{CO}_{2}$ prior to functional and phenotypical analysis. For human in vitro studies, human peripheral blood from healthy volunteers was purchased from Tianjin Blood Center (Tianjin, China). Peripheral blood mononuclear cells (PBMCs) were isolated with human Lymphoprep solution (Axis-shield PoC AS, Oslo, Norway) as per manufacturer's instructions, then cells were seeded in 10-cm petri-dish with 10 $\mathrm{ml}$ RPMI 1640 medium plus 10\% FBS and incubated for $2 \mathrm{~h}$ to allow cells to adhere to the surface. Adherent cells were harvested and induced to form immature DCs by culturing in RPMI 1640 medium containing $20 \% \mathrm{FBS}, 120 \mathrm{ng} \mathrm{ml}^{-1}$ recombinant human GM-CSF (PeproTech, USA) and $60 \mathrm{ng} \mathrm{ml}^{-1}$ recombinant human IL-4 (PeproTech, USA) for 5 days. Non-adherent cells were recovered and cultured in DMEM/F-12 medium containing 10\% FBS for 7 days and were used as mixed population of human lymphocytes.

Preparation of exosomes. Cell culture medium was sequentially centrifuged at $1000 \mathrm{~g}$ for $10 \mathrm{~min}$, followed by $10,000 \mathrm{~g}$ for $30 \mathrm{~min}$. The supernatant was collected and filtered with a $0.22-\mu \mathrm{m}$ filter (Millex, Germany), followed by ultracentrifugation at $100,000 \mathrm{~g}$ for $1 \mathrm{~h}$ to pellet exosomes. Exosome pellets were washed in a large volume of PBS and recovered by centrifugation at $100,000 \mathrm{~g}$ for $1 \mathrm{~h}$. The total protein concentration of exosomes was quantified by Bradford assay (Sangon Biotech, USA). For human serum exosome isolation approved by the institutional review board, human serum from healthy volunteers or cancer patients was obtained from Tianjin Blood Center (Tianjin, China) or from biobank of Tianjin Medical University Cancer Institute and Hospital (Tianjin, China), with the approval of the hospital ethic committee and Tianjin science and technology commission (Permit number (2016) 621). Serum was centrifuged at $3000 \mathrm{~g}, 6,000 \mathrm{~g}$, and $10,000 \mathrm{~g}$ twice for $30 \mathrm{~min}$ each time to remove cell debris, followed by filtration with $0.22-\mu \mathrm{m}$ filter (Millex, Germany). The supernatant was transferred into a fresh tube and pelleted by ultracentrifugation (Beckman Optimal-100 XP, Beckman Coulter, Germany) at $100,000 \mathrm{~g}$ for $1 \mathrm{~h}$ and further purified by sucrose density gradient centrifugation. Exosomes were layered on a linear sucrose gradient $(0.25 \mathrm{M}$, $0.45 \mathrm{M}, 0.65 \mathrm{M}, 0.85 \mathrm{M}, 1.05 \mathrm{M}, 1.25 \mathrm{M}, 1.45 \mathrm{M}, 1.65 \mathrm{M}$, and $1.85 \mathrm{M}$ sucrose, Sigma, China). The gradients were centrifuged for $18 \mathrm{~h}$ at $100,000 \mathrm{~g}$ at $4^{\circ} \mathrm{C}$. Six fractions from 0.65 to $1.65 \mathrm{M}$ sucrose gradients were collected and ultracentrifuged at
$100,000 \mathrm{~g}$ for $1 \mathrm{~h}$ at $4^{\circ} \mathrm{C}$ to pellet exosomes. The exosome pellets were dissolved in PBS and the total protein concentration of exosomes was quantified by the Bradford assay (Sangon Biotech, USA)

Characterization of exosomes. Exosomal morphology was visualized using a high-resolution transmission electron microscope (TEM, Hitachi HT7700, Tokyo, Japan $)^{19}$. Briefly, the resuspended exosomes were diluted into PBS $\left(1 \mu \mathrm{g} \mathrm{Il}^{-1}\right)$ and mixed with an equal volume of $4 \%$ paraformaldehyde. Exosomes were adsorbed onto a glow-discharged, carbon-coated formvar film attached to a metal specimen grid. Excess solution was blotted off and the grid was immersed with a small drop $(50 \mu \mathrm{l})$ of $1 \%$ glutaraldehyde for $5 \mathrm{~min}$ followed by washing with $100 \mu \mathrm{l}$ distilled water for eight times ( 2 min each time). Subsequently, the grid was transferred to $50 \mu \mathrm{l}$ uranyl-oxalate solution (pH7.0) for $5 \mathrm{~min}$ and then $50 \mu \mathrm{l}$ methyl celluloseuranyl acetate (100 $\mu \mathrm{l} 4 \%$ uranyl acetate and $900 \mu \mathrm{l} 2 \%$ methyl cellulose) for $10 \mathrm{~min}$ on ice. The excess solution was blotted off and the sample was dried and examined with TEM.

Antigen-specific assay. Subcutaneous HCC mice were established by subcutaneous injection of $0.1 \mathrm{ml}$ PBS containing Hepa1- 6 cells $\left(5 \times 10^{5}\right)$ into left axilla of $C 57 B L / 6$ mice ( $n=5,6-8$-week old) and allowed to grow for 7 days, followed by intravenous injection of $\mathrm{DC}_{\mathrm{TEX}(\mathrm{Hepa})}, \mathrm{DC}_{\mathrm{TEX}(\mathrm{Hepa})-\mathrm{N} 1 \mathrm{ND}}, \mathrm{DC}_{\mathrm{TEX}(\mathrm{Panc})-\mathrm{N} 1 \mathrm{ND}}$, and $\mathrm{DC}$ TEX(4T1)-N1ND at the dose of $2 \times 10^{6}$ cells once per week for 3 weeks. Tumor and splenocytes were harvested $48 \mathrm{~h}$ after last immunization for measurement. Splenocytes $\left(5 \times 10^{5}\right)$ per well were plated in 48 -well plates and cultured in fresh T lymphocyte medium containing AFP212 $\left(40 \mu \mathrm{g} \mathrm{ml}^{-1}\right)$, a known murine AFP epitope $^{20}$ (purchased from ChinaPeptides Co, Ltd, China), or without peptides for $72 \mathrm{~h}$. Levels of IFN- $\gamma$ and IL-2 were detected in supernatant of activated splenocytes per the manufacturer's instructions. For the tetramer staining, generation of AFP-specific tetramer was performed as per manufacturer's instructions (the QuickSwitchTM Quant H-2K tetramer kit; TB-7400-K1, MBL, USA) with AFP212 $(10 \mu \mathrm{M})$. Splenocytes from different treatment groups were treated with $50 \mathrm{nM}$ dasatinib (HY-10181, MCE, USA) for $30 \mathrm{~min}$ at $37^{\circ} \mathrm{C}$, followed by washing with washing buffer and stained with AFP-H- $2 \mathrm{~K}^{\mathrm{b}}$-tetramer-PE $\left(2 \mu \mathrm{g} \mathrm{ml}^{-1}\right)$ for $60 \mathrm{~min}$ at $4^{\circ} \mathrm{C}$. Subsequently, tetramer stained splenocytes were counterstained with FITC-anti -mouse CD3e (eBioscience, USA) and APC-anti-mouse-CD8a (Biolegend, USA). The stained cells were subjected to flow cytometric analysis with BD LSRFortessa and analyzed by FlowJo software (FlowJo, LLC).

MRI assessment. The magnetic resonance images of orthotopic HCC mice were acquired using $\mathrm{T} 2$ propeller sequence with the following parameters: slice thickness of $1.0 \mathrm{~mm}$, slice spacing of $0.5 \mathrm{~mm}$, TR/TE of $3494 / 70.7 \mathrm{~ms}$, matrix of $256 \times 160$, and FOV of $8 \times 8 \mathrm{~cm}(3.0$ Tesla MR scanner, Signa Excite HDx; GE healthcare, Milwaukee, WI, USA) with a small animal coil in Tianjin Medical University General Hospital. During the examination, mice were anesthetized with pentobarbital sodium and fixed to minimize body motion, respiration rate was monitored, and body temperature was maintained to be at $37^{\circ} \mathrm{C}$ using warm airflow. The tumor size was calculated based on MRI images for 3, 5, and 7 weeks in orthotopic HCC mice bearing large established tumor. Each mouse was marked and imaged with MRI at different time-points.

Peptide binding and cellular uptake assay. To measure the percentage of CD63positive exosomes in total exosomes, cellmask-labeled (Life Technologies, USA) exosomes $(5 \mu \mathrm{g})$ were incubated with phycoerythrin (PE)-cy7 anti-mouse CD63 antibody (1:500; eBioscience, USA) or PE-cy7 rat immunoglobulin G2a (IgG2a) isotype control (1:500; eBioscience, USA) in $4 \%$ BSA for $30 \mathrm{~min}$ at $4{ }^{\circ} \mathrm{C}$, followed by 1:10 dilution with PBS, and washed with PBS and filtered to remove unbound peptides before flow cytometry (BD LSRFortessa" cell analyzer, USA). To measure the binding affinity of N1ND-CP05 or N1ND on exosomes, PKH67-labeled (Sigma, USA) exosomes $(10 \mu \mathrm{g})$ derived from Hepa1-6, Panc02, or 4T1 were incubated with AF680-labeled peptides $(20 \mu \mathrm{g})$ overnight at $4{ }^{\circ} \mathrm{C}$, followed by washing with PBS for five times in 2-ml ultracentrifuge tubes and filtration with $100-\mathrm{kDa}$ diafiltration tube (Millipore, USA) to remove unbound peptides. Subsequently, peptide-exosome complexes $(30 \mu \mathrm{g})$ were measured by flow cytometry directly ${ }^{19}$. Briefly, to validate the flow cytometry assay for exosomes, we included (1) a buffer control to eliminate the background noise; (2) the resuspended pellet from a $100,000 \mathrm{~g}$ ultracentrifugation of cell culture medium to evaluate the background noise; (3) 100 and $200 \mathrm{~nm}$ reference beads to define the target exosome populations. Exosomes alone were used as negative controls for gating. To test the uptake of different peptide/ exosome complexes in murine BMDCs, PKH67-labeled exosomes $(40 \mu \mathrm{g})$ derived from Hepa1-6, Panc02, or 4T1 were pre-incubated with AF680-labeled peptides $(80 \mu \mathrm{g})$ overnight at $4{ }^{\circ} \mathrm{C}$, then added into BMDCs derived from either $C 57 B L / 6$ or $B A L B / C$ mice (on day 7 after differentiation) at $37^{\circ} \mathrm{C}$ in $5 \%$ $\mathrm{CO}_{2}$. Cells were analyzed with flow cytometry (BD LSRFortessa ${ }^{\mathrm{ax}}$ cell analyzer, USA) at $24 \mathrm{~h}$ after incubation. For measurement of cellular localization, PKH67labeled exosomes $(40 \mu \mathrm{g})$ derived from Hepa1- 6 cells were pre-incubated with AF680-labeled peptides $(80 \mu \mathrm{g})$ overnight at $4{ }^{\circ} \mathrm{C}$, then added into DCs (DC2.4) at $37^{\circ} \mathrm{C}$ in $5 \% \mathrm{CO}_{2}$ for $2 \mathrm{~h}$ or $24 \mathrm{~h}$, followed by observation with confocal fluorescence microscope (Olympus FV1000, Olympus, Japan). 
Western blot. Protein extraction and western blot were carried out as previously described $^{18}$. Various amounts of protein prepared from cell lysates and TEXs were loaded onto SDS-polyacrylamide gel $(10 \%)$. The membrane was then washed and blocked with $5 \%$ skimmed milk and probed for $1 \mathrm{~h}$ with different primary antibodies including mouse monoclonal antibodies: Alix (1:200; Cell signaling technology, USA) and GAPDH (1:1000; MultiSciences Biotech Co., Ltd, China); and rabbit polyclonal antibodies: $\beta$-actin (1:2000; Cell signaling technology, USA), CD63 (1:200, Santa Cruz, USA), HMGN1 (1:1000; ProteinTech, USA), AFP (1:2000; Abcam, UK), TLR4 (1:1000; ProteinTech, USA), MyD88 (1:1000; Cell signaling, USA), and TRAF6 (1:5000; Abcam, UK), respectively. The bound primary antibodies were detected by peroxidase-conjugated goat anti-mouse, rabbit anti-mouse, or goat anti-rabbit IgGs (1:5000; Sigma, USA), respectively, and the ECL western blot analysis system (Millipore, Billerica, MA) was used. Uncropped images of all western blots can be found in Supplementary Fig. 10.

Flow cytometry and intracellular staining. For the detection of murine DC or BMDC surface markers, DCs or BMDCs were washed in FACS buffer (PBS containing $0.5 \%$ BSA and $0.05 \% \mathrm{NaN} 3$ ) and stained with FITC-anti-mouse IgG2b Isotype (1:500), PE-anti-mouse IgG2b Isotype (1:500), APC-anti-mouse IgG2b Isotype (1:500; Biolegend, USA), PE-cy7-anti-mouse IgG2b Isotype (1:500; eBioscience, USA), PE-cy7 anti-mouse CD63 (1:500; eBioscience, USA), FITC-antimouse MHC I (1:250; eBioscience, USA), FITC-anti-mouse MHC II (1:250; Biolegend, USA), FITC-anti-mouse CD80 (1:250; Abcam, UK), PE-anti-mouse CD83, and APC-anti-mouse CD86 (1:250; eBioscience, USA), and PE-cy5.5 anti-mouse CD11c (1:250; eBioscience, USA) on ice for $30 \mathrm{~min}$ prior to flow cytometry. For the detection of various subsets of leukocytes including NK cells, T lymphocytes and B cells in blood, lymphoid organs or tumor tissues, single-cell suspensions from different tissues were stained with FITC- or Percp-cy5.5-anti-mouse CD45 (1:500; Biolegend, USA), FITC-, PE-, or PE-cy7-anti-mouse CD3e (1:500; eBioscience, USA), PE-anti-mouse CD4 (1:500; eBioscience, USA), APC-anti-mouse-CD8a (1:500; Biolegend, USA), PE-anti-mouse CD11c (1:250; Biolegend, USA), BV421anti-mouse-CD11b (1:500; Biolegend, USA), FITC-anti-mouse-B220/CD45R (1:500; eBioscience, USA), PE-cy7 anti-mouse-CD19 (1:500; Biolegend, USA), APC-anti-mouse-NK1.1 (1:500; eBioscience, USA), PE-cy7-anti-mouse-CD25 (1:500; eBioscience, USA), PE-anti-mouse-CD62L (1:500; eBioscience, USA), FITC-anti-mouse-CD44 (1:500; eBioscience, USA), PE-cy7 anti-mouse-CD127 (1:500; eBioscience, USA), and eFluro450-anti-mouse CCR7 (1:250; eBioscience, USA). For the detection of various subsets of lymphocytes derived from human PBMC, cells were stained with PE-anti-human CD45 (1:500; Biolegend, USA), PEcy5-anti-human CD3e (1:500; Biolegend, USA), APC-anti-human CD4 (1:500; Biolegend, USA), FITC-anti-human-B220/CD45R (1:500; eBioscience, USA), FITC-anti-human-CD8 $\alpha$ (1:500; Biolegend, USA), FITC-anti-human-CD56 (1:500; Biolegend, USA), and APC-anti-human CD19 (1:500; Biolegend, USA). Cells were washed with FACS buffer for three times after staining followed by flow cytometry (BD LSRFortessa ${ }^{\mathrm{Tx}}$ cell analyzer, USA). All data were analyzed with the software FlowJo (Tree Star Inc., Ashland, OR, USA). Flow cytometry data were acquired by BD LSRFortessa, and analyzed by FlowJo software (FlowJo, LLC).

Cytokine release and cytolysis assay. Murine DCs or BMDCs were pulsed with N1ND-modified Hepa1-6, Panc02, and 4T1 TEXs or exosomes from HCC, pancreatic cancer, and breast cancer patients' serum and incubated for $48 \mathrm{~h}$ at the final concentration of $40 \mu \mathrm{g} \mathrm{ml}^{-1}$, respectively. Mixed splenic T lymphocytes were harvested from unimmunized $C 57 B L / 6$ or $B A L B / C$ mice and incubated with (BM) $\mathrm{DC}_{\mathrm{TEX}-\mathrm{N} 1 \mathrm{ND}}$ or (BM)DC $\mathrm{C}_{\mathrm{TEX}}$ for 3 days. Levels of IFN- $\gamma$ and IL-2 in supernatant were detected in activated T lymphocytes per the manufacturer's instructions. For mouse in vitro study, IFN- $\gamma$ and IL-2 ELISA kits were purchased from R\&D systems and eBioscience (USA). For in vivo cytokine assay, mouse blood was harvested from orthotopic tumor-bearing mice 2 days after the last immunization and centrifuged at $3000 \mathrm{~g}$ for $30 \mathrm{~min}$ at room temperature, followed by analysis of IFN- $\gamma$ (R\&D systems, USA), IL-10, and TGF- $\beta$ (eBioscience, USA), respectively. For human cytolysis assay, mixed population of lymphocytes derived from human PBMC were co-cultured with human DC activated by TEX-N1ND for 3 days. Subsequently, activated human lymphocytes were tested again different human cancer cells. The cytotoxicity detection kit (R\&D systems, USA) was used to measure the cytolysis rate elicited by effector $\mathrm{T}$ cells against different tumor cells. For the cytolysis assay, $1 \times 10^{5}$ effector T cells (E) were used to lyse against $1 \times 10^{4}$ target cells (T) with an E:T ratio of 10:1. For other E:T ratios, the number of target cells remained the same while the number of effector $\mathrm{T}$ cells changed accordingly. The amount of lactate dehydrogenase (LDH) released from lysed target cells was used as an indicator for cytolysis. Cytolysis rate (\%) was calculated based on the equation: cytotoxicity $(\%)=((($ effector/target cell $\mathrm{mix}-$ effector cell control $)-$ low control)/(high control - low control) $) \times 100$ as per manufacturer's instructions (Roche, CA, USA).

Isolation of leukocytes from mouse blood and tissues. Blood from ectopic and orthotopic tumor-bearing mice treated with (BM)DC TEX-N1ND, $_{\text {(BM)DC }}$ TEX, (BM) DC, or PBS was collected with $1 \%$ heparin, followed by addition of equal volume of Lymphoprep $^{\text {ts }}$ (Stemcell Technologies, Canada) and lysis with the ammonium chloride-potassium (ACK) lysis buffer for $5 \mathrm{~min}$ at room temperature to generate lymphocyte suspensions. Isolation of T lymphocytes from mouse tumor tissues was adopted ${ }^{37}$. Briefly, tumor tissues were minced into small pieces with surgical scissors, gently forced through a $200-\mu \mathrm{m}$-gauge stainless steel mesh with a sterile syringe plunger and digested in collagenase type IV suspension $\left(0.05 \mathrm{mg} \mathrm{ml}^{-1}\right.$, Worthington Biochem. Corp., USA) for $40 \mathrm{~min}$ at $37^{\circ} \mathrm{C}$. The resulting suspension was filtered through the $70-\mu \mathrm{m}$ cell strainer. The extract was centrifuged at $528 \mathrm{~g}$ for $10 \mathrm{~min}$ and the supernatant was removed. The mixture was resuspended with $10 \mathrm{ml} \mathrm{40 \%} \mathrm{percoll} \mathrm{(Pharmacia,} \mathrm{Sweden)} \mathrm{followed} \mathrm{by} \mathrm{centrifugation} \mathrm{at} 850 \mathrm{~g}$ for $30 \mathrm{~min}$ at $22^{\circ} \mathrm{C}$ to remove the supernatant. Cell pellets were resuspended in ACK lysis buffer to remove red blood cells and the rest cells were stained with different fluorescence-labeled antibodies as described above.

Immunohistochemistry and histological staining. To examine the presence of $\mathrm{CD}^{+} \mathrm{T}$ and Treg lymphocytes in tumor sections from orthotopic HCC mice treated with $\mathrm{DC}_{\mathrm{TEX}-\mathrm{N} \text { IND }}$ or control groups, mouse tumor tissues were fixed in Bouin's solution (Sigma, USA) and embedded with paraffin. $\mathrm{CD}^{+}$or Foxp $3^{+} \mathrm{T}$ lymphocytes were stained with rabbit anti-mouse polyclonal antibodies CD3 (1:2000; Novus, USA) or Foxp3 (1:2000; Abcam, UK), respectively, and detected by goat anti-rabbit secondary antibody (1:5000; Sigma, USA). Routine Hematoxylin and eosin (H\&E) staining was used to examine the pulmonary metastasis of lung tissues from orthotopic HCC mouse models. Briefly, tissues were fixed in Bouin's solution and embedded with paraffin followed by staining with hematoxylin and eosin. The slides were incubated in filtered $0.1 \%$ Mayer's haematoxylin for $10 \mathrm{~min}$ for nucleus and ribosome staining. Afterwards, sections were rinsed in coolrunning distilled $\mathrm{H}_{2} \mathrm{O}$ to remove excessive haematoxylin, and treated with $0.5 \%$ hydrochloric acid, and $1 \%$ sodium bicarbonate solution, respectively. After that, sections were incubated in $0.5 \%$ eosin $(0.5 \mathrm{~g}$ dissolved in $100 \mathrm{ml}$ of $95 \% \mathrm{EtOH})$ for $5 \mathrm{~min}$ for cytoplasm staining, and washed by distilled $\mathrm{H}_{2} \mathrm{O}$. The sections were dehydrated in ingredients of 70, 80, 95, 100, 100\% EtOH for 5 min each. Finally, sections were treated in xylene for $10 \mathrm{~min}$ and coverslips were mounted with neutral gum, followed by visualization with an inverted microscope (OLYMPUS, Tokyo, Japan).

Tissue distribution. To examine the biodistribution $\mathrm{DC}_{\mathrm{TEX}-\mathrm{N} 1 \mathrm{ND}}$ or $\mathrm{DC}_{\mathrm{TEX}}$ in orthotopic C57BL/6 HCC mice, PE-DiI-labeled (ThermoFisher, USA) DC TEX-N1ND, $_{\text {, }}$ $\mathrm{DC}_{\mathrm{TEX}}$, or DC $\left(5 \times 10^{6}\right)$ were administered intravenously into orthotopic C57/BL6 HCC mice for single injection. Liver, tumor, mesenteric lymph node, inguinal lymph node, kidney, and spleen were harvested $48 \mathrm{~h}$ after injection for imaging with IVIS spectrum (PE, Waltham, MA, USA).

In vitro assay for $\mathbf{T}$ cell activation and proliferation. To examine the effect of $\mathrm{DC}_{\mathrm{TEX}-\mathrm{N} 1 \mathrm{ND}}$ on memory and naive $\mathrm{T}$ cells, wild-type $\mathrm{C57BL} / 6$ mice were immunized with $\mathrm{DC}_{\mathrm{TEX}}\left(2 \times 10^{6}\right)$ intravenously for once per week for 3 weeks and splenocytes were harvested 4 weeks post vaccination. T cell subsets including $\mathrm{CD}^{+}$ $\mathrm{CD} 44^{\text {high }} \mathrm{CD} 62 \mathrm{~L}^{\text {high/low }}$ memory and $\mathrm{CD} 8{ }^{+} \mathrm{CD} 44^{\text {low }} \mathrm{CD} 62 \mathrm{~L}^{\text {high }}$ naive $\mathrm{T}$ cells were isolated with FACS sorting with BD FACSAriall (BD Biosciences, USA). Memory or naive $\mathrm{T}$ cells $\left(3 \times 10^{5}\right)$ were then incubated with $\mathrm{DC}_{\mathrm{TEX}}$ or $\mathrm{DC}_{\mathrm{TEX}-\mathrm{N} 1 \mathrm{ND}}\left(3 \times 10^{4}\right)$ for 3 or 6 days in 96-well plates. On day 3 or 6 after co-incubation, each CD8 ${ }^{+} \mathrm{T}$ cell subset in treated samples was analyzed by flow cytometry.

T cell adoptive transfer. $C 57 B L / 6$ mice were immunized with $\mathrm{DC}_{\mathrm{TEX}-\mathrm{N} 1 \mathrm{ND}}(2 \times$ $10^{6}$ ) once per week for 3 weeks. CD ${ }^{+} \mathrm{CD} 44^{\text {high }} \mathrm{CD} 62 \mathrm{~L}^{\text {high/low }}$ memory T cell subsets were harvested from spleen and lymph nodes of immunized mice 4 weeks after last immunization by flow cytometry sorting with BD FACSAriall (BD Biosciences, USA). CD8 ${ }^{+} \mathrm{CD} 44^{\text {high }} \mathrm{CD} 62 \mathrm{~L}^{\text {high/low }}$ memory $\mathrm{T}$ cells $\left(5 \times 10^{6}\right)$ were injected intravenously into day-7-established orthotopic HCC mice for once. $\mathrm{DC}_{\mathrm{TEX}-\mathrm{N} 1 \mathrm{ND}}$ was administered as a positive control with the same dosing regimen as used in the immunization protocol. The tumor volume was measure 2 weeks after treatment as described above.

Generation of TLR4/TRAF6-deficient DC cell lines. DC2.4 were transfected with CRISPR/Cas9-expressing lentivirus (Lentiviral CRISPR Toolbox, Zhang lab, USA) followed by $2 \mu \mathrm{g} \mathrm{ml}^{-1}$ blasticidin selection for 1 week. Cas9-expressing DC2.4 cells were transfected with sgRNA-expressing lentivirus for $12 \mathrm{~h}$, followed by $0.5 \mu \mathrm{g} \mathrm{ml}^{-1}$ puromycin selection for 2 weeks. sgRNAs targeting murine TLR4 and TRAF6 genes were designed with the CRISPR/Cas9 Target Online Predictor (crispr.cos.uniheidelberg.de, University of Heidelberg, Germany $)^{38}$. The TLR4 gene target sgRNA sequences were 5'-CACCGAGAGTCCTAGCCAGGAGCCA-3', 5'-AAACTGGCT CCTGGCTAGGACTCTC-3'; the TRAF6 gene target sgRNA sequences were $5^{\prime}$ CACCGTTAAACTGTGAGAACAGCTG- $3^{\prime}$ and $5^{\prime}$-AAACCAGC TGTTCTCA CAGTTTAAC-3', respectively. These sgRNAs were cloned into a LentiGuide-puro vector at BsmBI site as previously reported ${ }^{39}$.

Statistical analysis. All data are presented as means \pm s.e.m. Statistical differences between treated and control groups were evaluated by SigmaStat (Systat Software). Both parametric and nonparametric analyses were applied as specified in figure legends. Sample size was determined by $\mathrm{G}^{*}$ Power 3.1.7 (Power analysis and Sample size). Significance was determined based in $p<0.05$. 
Reporting summary. Further information on research design is available in the Nature Research Reporting Summary linked to this article.

\section{Data availability}

The source data underlying Figs. 1a, e-h, 2a-g, 3b, d, e, 4a, b, d-f, 5a-j, 6a-g, 7a-d and Supplementary Figs. 1a, b, 2d-f, 3a, d, e, 4a, b, 5b-e, 7a, b, d, e, 8a, c, d, 9a and c are provided as a Source Data file. All the other data supporting the findings of this study are available within the article and its supplementary information files and from the corresponding author upon reasonable request.

Received: 13 May 2019; Accepted: 17 March 2020;

Published online: 14 April 2020

\section{References}

1. Anguille, S., Smits, E. L., Lion, E., van Tendeloo, V. F. \& Berneman, Z. N. Clinical use of dendritic cells for cancer therapy. Lancet Oncol. 15, e257-e267 (2014).

2. Bryant C. E. et al. Dendritic cells as cancer therapeutics. Semin. Cell Dev. Biol. 86, 77-88 (2019).

3. Graff, J. N. \& Chamberlain, E. D. Sipuleucel-T in the treatment of prostate cancer: an evidence-based review of its place in therapy. Core Evid. 10, 1-10 (2015).

4. Sabado, R. L., Balan, S. \& Bhardwaj, N. Dendritic cell-based immunotherapy. Cell Res. 27, 74-95 (2017).

5. Hargadon, K. M. Strategies to improve the efficacy of dendritic cell-based immunotherapy for melanoma. Front. Immunol. 8, 1594 (2017).

6. Castiello, L. et al. Monocyte-derived DC maturation strategies and related pathways: a transcriptional view. Cancer Immunol. Immunother. 60, 457-466 (2011).

7. Krawczyk, C. M. et al. Toll-like receptor-induced changes in glycolytic metabolism regulate dendritic cell activation. Blood 115, 4742-4749 (2010).

8. Zhu, M., Xu, W., Su, H., Huang, Q. \& Wang, B. Addition of CpG ODN and Poly (I:C) to a standard maturation cocktail generates monocyte-derived dendritic cells and induces a potent Th1 polarization with migratory capacity. Hum. Vaccin. Immunother. 11, 1596-1605 (2015).

9. Degen, W. G., Jansen, T. \& Schijns, V. E. Vaccine adjuvant technology: from mechanistic concepts to practical applications. Expert Rev. Vaccines 2 327-335 (2003).

10. Pulendran, B. \& Ahmed, R. Translating innate immunity into immunological memory: implications for vaccine development. Cell 124, 849-863 (2006).

11. Rydyznski, C. E. \& Waggoner, S. N. Boosting vaccine efficacy the natural (killer) way. Trends Immunol. 36, 536-546 (2015).

12. Yang, D. et al. High-mobility group nucleosome-binding protein 1 acts as an alarmin and is critical for lipopolysaccharide-induced immune responses. $J$. Exp. Med. 209, 157-171 (2012).

13. Wei, F. et al. The Alarmin HMGN1 contributes to antitumor immunity and is a potent immunoadjuvant. Cancer Res. 74, 5989-5998 (2014).

14. Nie, Y. et al. Development of a curative therapeutic vaccine (TheraVac) for the treatment of large established tumors. Sci. Rep. 7, 14186 (2017).

15. Han, Z., Yang, Trivett, A. \& Oppenheim, J. J. Therapeutic vaccine to cure large mouse hepatocellular carcinomas. Oncotarget 8, 52061-52071 (2017).

16. Wolfers, J. et al. Tumor-derived exosomes are a source of shared tumor rejection antigens for CTL cross-priming. Nat. Med. 7, 297-303 (2001).

17. Mahaweni N. M., Kaijen-Lambers M. E., Dekkers J., Aerts J. G., Hegmans J. P. Tumour-derived exosomes as antigen delivery carriers in dendritic cell-based immunotherapy for malignant mesothelioma. J. Extracell. Vesicles 2, 22492 (2013).

18. Rao, Q. et al. Tumor-derived exosomes elicit tumor suppression in murine hepatocellular carcinoma models and humans in vitro. Hepatology 64, 456-472 (2016).

19. Gao X. et al. Anchor peptide captures, targets, and loads exosomes of diverse origins for diagnostics and therapy. Sci. Transl. Med. 10, eaat0195 (2018).

20. Hong, Y. et al. Epitope-optimized alpha-fetoprotein genetic vaccines prevent carcinogen-induced murine autochthonous hepatocellular carcinoma. Hepatology 59, 1448-1458 (2014).

21. Pitt, J. M. et al. Targeting the tumor microenvironment: removing obstruction to anticancer immune responses and immunotherapy. Ann. Oncol. 27, 1482-1492 (2016).

22. Badovinac, V. P., Messingham, K. A., Jabbari, A., Haring, J. S. \& Harty, J. T. Accelerated CD8+ T-cell memory and prime-boost response after dendriticcell vaccination. Nat. Med. 11, 748-756 (2005)

23. Rivino, L. et al. Chemokine receptor expression identifies Pre-T helper (Th)1, Pre-Th2, and nonpolarized cells among human CD4+ central memory T cells. J. Exp. Med 200, 725-735 (2004)
24. Sallusto, F., Geginat, J. \& Lanzavecchia, A. Central memory and effector memory T cell subsets: function, generation, and maintenance. Annu. Rev. Immunol. 22, 745-763 (2004).

25. Bachmann, M. F., Wolint, P., Schwarz, K., Jager, P. \& Oxenius, A. Functional properties and lineage relationship of CD8 $+\mathrm{T}$ cell subsets identified by expression of IL-7 receptor alpha and CD62L. J. Immunol. 175, 4686-4696 (2005).

26. Ridolfi, R. et al. Evaluation of in vivo labelled dendritic cell migration in cancer patients. J. Transl. Med. 2, 27 (2004).

27. De Vries, I. J. et al. Effective migration of antigen-pulsed dendritic cells to lymph nodes in melanoma patients is determined by their maturation state. Cancer Res. 63, 12-17 (2003).

28. Yang, D., Bustin, M. \& Oppenheim, J. J. Harnessing the alarmin HMGN1 for anticancer therapy. Immunotherapy 7, 1129-1131 (2015).

29. Yang, J. D., Nakamura, I. \& Roberts, L. R. The tumor microenvironment in hepatocellular carcinoma: current status and therapeutic targets. Semin. Cancer Biol. 21, 35-43 (2011).

30. Yang, D., de la Rosa, G., Tewary, P. \& Oppenheim, J. J. Alarmins link neutrophils and dendritic cells. Trends Immunol. 30, 531-537 (2009).

31. Lu, Z. et al. Dendritic cell-derived exosomes elicit tumor regression in autochthonous hepatocellular carcinoma mouse models. J. Hepatol. 67 739-748 (2017).

32. Shen, Z., Reznikoff, G., Dranoff, G. \& Rock, K. L. Cloned dendritic cells can present exogenous antigens on both MHC class I and class II molecules. J Immunol. 158, 2723-2730 (1997).

33. Ho, M. Y. et al. IL-27 directly restrains lung tumorigenicity by suppressing cyclooxygenase-2-mediated activities. J. Immunol. 183, 6217-6226 (2009).

34. Bhadury, J., Lopez, M. D., Muralidharan, S. V., Nilsson, L. M. \& Nilsson, J. A. Identification of tumorigenic and therapeutically actionable mutations in transplantable mouse tumor cells by exome sequencing. Oncogenesis 2, e44 (2013).

35. Knowles, B. B., Howe, C. C. \& Aden, D. P. Human hepatocellular carcinoma cell lines secrete the major plasma proteins and hepatitis B surface antigen. Science 209, 497-499 (1980).

36. Matheu M. P., Sen D., Cahalan M. D., Parker I. Generation of bone marrow derived murine dendritic cells for use in 2-photon imaging. J. Vis. Exp. 17, 773 (2008).

37. Blom, K. G. et al. Isolation of murine intrahepatic immune cells employing a modified procedure for mechanical disruption and functional characterization of the B, T and natural killer T cells obtained. Clin. Exp. Immunol. 155, 320-329 (2009)

38. Stemmer, M., Thumberger, T., Del Sol Keyer, M., Wittbrodt, J. \& Mateo, J. L. CCTop: an intuitive, flexible and reliable CRISPR/Cas9 target prediction tool. PLoS One 10, e0124633 (2015).

39. Sanjana, N. E., Shalem, O. \& Zhang, F. Improved vectors and genome-wide libraries for CRISPR screening. Nat. Methods 11, 783-784 (2014).

\section{Acknowledgements}

The authors thank Dr Yiqi Seow (Biomedical Sciences Institutes, A*STAR, Singapore) for critical review of the paper. This research was supported by National Key R\&D Program of China (no.2017YFC1001902), National Natural Science Foundation of China (no. 81803416, 81672124, 81501531, and 81671528), the Science \& Technology Development Fund of Tianjin Education Commission for Higher Education (Grant no. 2017KJ222) and Tianjin Municipal 13th five-year plan (Tianjin Medical University Talent Project).

\section{Author contributions}

H.Y. and B.Z. designed the project. B.Z., H.Q., Z.L., L.C., B.S., R.Y., Y.Z., Z.L., X.G., A.Y. L.W., R.J., and Q.Z. carried out the experiments; B.Z. and H.Y. analyzed the data; H.Y. and B.Z. wrote the paper with the input from all authors.

\section{Competing interests}

The authors declare no competing interests.

\section{Additional information}

Supplementary information is available for this paper at https://doi.org/10.1038/s41467 020-15569-2.

Correspondence and requests for materials should be addressed to H.Y.

Peer review information Nature Communications thanks Joost Oppenheim and the other, anonymous, reviewer(s) for their contribution to the peer review of this work

Reprints and permission information is available at http://www.nature.com/reprints

Publisher's note Springer Nature remains neutral with regard to jurisdictional claims in published maps and institutional affiliations. 
(c) (i) Open Access This article is licensed under a Creative Commons Attribution 4.0 International License, which permits use, sharing, adaptation, distribution and reproduction in any medium or format, as long as you give appropriate credit to the original author(s) and the source, provide a link to the Creative Commons license, and indicate if changes were made. The images or other third party material in this article are included in the article's Creative Commons license, unless indicated otherwise in a credit line to the material. If material is not included in the article's Creative Commons license and your intended use is not permitted by statutory regulation or exceeds the permitted use, you will need to obtain permission directly from the copyright holder. To view a copy of this license, visit http://creativecommons.org/ licenses/by/4.0/.

(C) The Author(s) 2020 